\title{
Origin and sedimentation characteristics of copper droplets sticking to spinel solids in pyrometallurgical slags
}

Evelien De Wilde ${ }^{1}$, Inge Bellemans ${ }^{1}$, Lichun Zheng $^{2}$, Mieke Campforts ${ }^{3}$, Muxing Guo ${ }^{2}$, Bart

Blanpain $^{2}$, Nele Moelans ${ }^{2}$, Kim Verbeken $^{1}$

1: $\quad$ Ghent University - Department of Materials Science and Engineering Technologiepark 903

B-9052 Zwijnaarde (Ghent) - Belgium

2: $\quad$ KU Leuven- Department of Materials Engineering

Kasteelpark Arenberg 44, bus 2450

B-3001 Heverlee (Leuven) - Belgium

3: $\quad$ Umicore R\&D

Kasteelstraat 7

B-2250 Olen - Belgium

CORRESPONDING AUTHOR

Inge Bellemans

Ghent University - Department of Materials Science and Engineering

Technologiepark 903

B-9052 Zwijnaarde (Ghent) - Belgium

+3293310441

Inge.Bellemans@UGent.be

\section{Abstract}

Cu-droplet losses in slags are an important problem in Cu-industry, limiting the metal recovery. An important cause responsible for the entrainment of copper droplet losses in slags is their sticking behaviour to spinel solids. In the present study, the interaction between spinel solids and $\mathrm{Cu}$-droplets is investigated in an industrially relevant slag system ( $\mathrm{PbO}-\mathrm{CaO}-\mathrm{SiO}_{2}-\mathrm{Cu}_{2} \mathrm{O}-$ $\mathrm{Al}_{2} \mathrm{O}_{3}-\mathrm{FeO}-\mathrm{ZnO}$ ) using two complementary experimental set-ups. Firstly the influence of the sedimentation time is studied and secondly the presence of entrained (sticking) droplets is studied as a function of height in the slag layer. Based on the experimental results, a mechanism that explains the sticking Cu-droplets is proposed. Finally, a model describing the sedimentation of sticking and non-sticking droplets is formulated based on the experimental data.

\section{Keywords}

Metal entrainment; Slag; Spinel; Copper production 


\section{Introduction}

Copper losses in primary and secondary copper production are a very important factor confining the overall metal recovery. ${ }^{1}$ To further limit metal losses, it would be tremendously helpful to acquire a more fundamental understanding of their characteristics and origin.

In literature it is generally well accepted that copper losses in slags are of chemical and mechanical nature. ${ }^{2-4}$ Chemical copper losses are caused by the formation and dissolution of copper sulphide and/or copper oxide during primary copper production and mainly as oxide for secondary production. This type of losses is intrinsically linked to pyrometallurgical processes, and is determined by the system's thermodynamics. The main influencing factors are the oxygen partial pressure ${ }^{2,5-7}$, the temperature, the composition of the slag and matte $e^{2,5-7}$ and the chemical activity of the metal oxide or sulphide. ${ }^{2}$

Mechanically entrained copper refers to entrapped or floating unsettled droplets. In primary copper production, both matte and metallic droplets are entrained, while in secondary copper production mainly metallic copper droplets are found. Mechanically entrained droplets can be attributed to a variety of causes. A first important source is the dispersion of copper or matte that precipitated due to a decrease of the copper solubility in the slag. This decrease is linked to inhomogeneity of the process due to, for example, zones with a different local oxygen potential or a lower temperature. ${ }^{8}$ A second cause is given by gas-producing reactions that disperse metal into the slag. In this respect, Minto and Davenport ${ }^{9}$ suggested that $\mathrm{SO}_{2}$ bubbles, nucleated at the bottom of the furnace, can elevate a surface film of matte into the slag ${ }^{8-10}$. A third important source is caused by operational actions such as charging or tapping, typically performed in pyrometallurgical processes. During tapping, mechanical entrainment can occur due to rise of the denser liquid phase, which can take place while flowing around obstacles in the vessel. ${ }^{3}$ The physical dispersion of the denser layer into the slag by mixing can originate from several causes such as gas injections, turbulence or pouring of one phase into the other. ${ }^{3,11}$ Finally, the penetration of metallic copper into refractory can also lead to metal loss. ${ }^{12}$

The abovementioned sources have been examined extensively in literature. However, a possibly important additional source of mechanically entrained droplets which has been omitted in most studies is the attachment of droplets to solids in slags, hampering the sedimentation. These solids have often been found to have a spinel structure. This observation was reported by Ip and Toguri $^{8}$ and Andrews ${ }^{11}$, and demonstrated for a synthetic slag system in previous work. ${ }^{13}$ Although the phenomenon was clearly observed, limited experimental or industrial data and fundamental knowledge is available. ${ }^{6}$

A wide variety of methodologies are typically used in literature to study metal loss in slags. A first commonly used approach are by water-based systems, representing the phases present at high temperatures. The dispersion of one liquid into another was studied using oil/water ${ }^{14,15}$, oil/mercury ${ }^{16}$, kerosene/water ${ }^{3,17}$ and paraffin-wax/water ${ }^{3}$ systems. A second method is the use of models like phase field models ${ }^{18}$, computational fluid dynamics ${ }^{19}$ or other numerical models ${ }^{20}$, simulating the process. A third frequently used approach is to study metal losses in slags by industrial and/or lab scale sampling procedures using industrial and/or synthetic slags. ${ }^{6}$ 
21-24 Profound analyses of the samples, combined with mass balances and thermodynamic analysis have revealed valuable insights. Despite the large efforts, limited attention has been given on the nature of the sticking behaviour of metal droplets onto solid particles in the slag.

The objective of the present study was to investigate the sedimentation of entrained copper droplets in slags. Specific attention will be given to droplets sticking to spinel particles.

Therefore two complementary experiments have been performed, using an industrially relevant synthetic slag system, namely $\mathrm{PbO}-\mathrm{CaO}-\mathrm{SiO}_{2}-\mathrm{Cu}_{2} \mathrm{O}-\mathrm{Al}_{2} \mathrm{O}_{3}-\mathrm{FeO}-\mathrm{ZnO}$. In a first experiment the influence of time on the sedimentation of the sticking and non-sticking copper alloy droplets will be studied. In an additional experiment, the presence of sticking and non-sticking copper alloy droplets will be studied as a function of the height in the slag layer.

\section{Experimental methods and materials}

Two types of experiments were performed to study the phenomenon of sticking droplets. In the first type, the presence of copper droplets sticking to spinel solids in the upper slag layer was measured as a function of time (set-up A). In the second type, the presence of copper droplets sticking to spinel solids in the slag was measured as a function of height for two different sedimentation times (set-up B).

\subsection{Set-up A: Study of the presence of copper droplets sticking to spinel solids as a function of time in the upper slag layer}

A slag composition in the spinel primary phase field of the synthetic slag system $\mathrm{PbO}-\mathrm{CaO}-\mathrm{SiO}_{2}-$ $\mathrm{ZnO}-\mathrm{Al}_{2} \mathrm{O}_{3}-\mathrm{FeO}-\mathrm{Cu}_{2} \mathrm{O}$ was selected based on thermodynamic calculations using the FactSage 6.4 thermochemical package (FACT and FTOxid database). The selected target slag composition is shown in Table 1. The slag is produced by mixing different pure oxides powders in the desired ratio. FeO was added as a combination of hematite and metallic iron, $\mathrm{CaO}$ was added as limestone. Cu was added under the metallic form and oxidized partially under the applied experimental conditions. All components had purity levels higher than $99 \mathrm{wt} \% .400 \mathrm{~g}$ of the mixture was weighed, mixed and transferred to an $\mathrm{Al}_{2} \mathrm{O}_{3}$ crucible $(270 \mathrm{ml}$ ) (diameter: $49 \mathrm{~mm}$ ). The $\mathrm{Al}_{2} \mathrm{O}_{3}$ crucible, surrounded by a protective $\mathrm{SiC}$ crucible, was heated in an inductive furnace at a rate of $600^{\circ} \mathrm{C} / \mathrm{h}$ (Indutherm, MU3000) up to a temperature of $800^{\circ} \mathrm{C}$, while a protective $\mathrm{N}_{2}$ atmosphere was established above the slag. At $800^{\circ} \mathrm{C}$, the $\mathrm{N}_{2}$ atmosphere was replaced by a $\mathrm{CO} /$ air mixture with volume ratio $1 / 2.44$, corresponding to an oxygen partial pressure $\left(p_{\mathrm{O}_{2}}\right)$ of

$10^{-7} \mathrm{~atm}$, with a total flow rate of $60 \mathrm{l} / \mathrm{h}$, which was kept constant throughout the rest of the experiment. Subsequently the slag was heated up to $1200^{\circ} \mathrm{C}$ and kept there for $20 \mathrm{~min}$ to be sure that the slag was completely molten. Each experiment was carried out with a thermocouple positioned in the slag in the crucible. Based on this measured temperature, the furnace temperature was controlled. $\mathrm{N}_{2}(60 \mathrm{l} / \mathrm{h})$ was bubbled for $5 \mathrm{~min}$ through the slag to homogenize the slag. At this point, the slag was not given time to reach thermodynamic equilibrium before the start of the experiment. It is assumed that in a timeframe of 30 minutes, the system did not reach equilibrium. This assumption was made based on the overview paper of Jak and Hayes ${ }^{25}$ on phase equilibria in slags and on experiments performed by Hidayat et al. ${ }^{26,}$ 
${ }^{27}$, who applied equilibration times of $24 \mathrm{~h}$ for $0.2 \mathrm{~g}$ of slag. At several times $(5,10,20,30,60$ and 90 min after the end of bubbling), samples were taken from the upper slag layer $(2 \mathrm{~cm}-3 \mathrm{~cm})$. A sample was taken by rapidly dipping a cold bar into the molten slag, such that a layer of slag 'sticks' to the sampling bar. Subsequently the bar was cooled in water. The slag granules were dried in a drying chamber at $150^{\circ} \mathrm{C}$.

\begin{tabular}{llllllll}
\hline & $\mathrm{ZnO}$ & $\mathrm{PbO}$ & $\mathrm{SiO}_{\mathbf{2}}$ & $\mathbf{A l}_{2} \mathbf{O}_{\mathbf{3}}$ & $\mathrm{Cu}$ & $\mathrm{CaO}$ & $\mathrm{FeO}$ \\
\hline wt\% & 6.5 & 39.3 & 13.8 & 7.3 & 3.9 & 9.8 & 19.4 \\
\hline
\end{tabular}

Table 1 Target synthetic slag composition, chosen based on FactSage calculations

A representative slag sample of each dipping sample was embedded in epoxy resin, ground and polished using $9 \mu \mathrm{m}$ and $3 \mu \mathrm{m}$ diamond paste. Subsequently, the samples were analysed using light optical microscopy (Keyence VHX-S90BE, LOM) and electron probe microanalysis (EPMA JEOL JXA-8530F). The LOM pictures were used to determine the area $\%$ of the entrained copper droplets and the spinel particles present in the slag by using the VHX software (VHX-2000E). The area fraction of the droplets was extracted based on the colour range of the droplets. The area fraction of the spinel particles was based on the brightness of the spinel particles.

The samples were coated with a conductive carbon layer. Subsequently both the microstructure and the composition of the different phases were analysed using a fully quantitative EPMAwavelength dispersive analysis (EPMA-WDS JEOL JXA-8530F) system, applying an acceleration voltage of $15 \mathrm{kV}$ and a probe current of $15 \mathrm{nA}$. The EPMA was used in backscattered electrons (BSE) mode for imaging. One of the limitations of EPMA is the fact that the microprobe analyses for the elements are reported as oxides, not as cations; therefore, cation proportions and mineral formulae must be recalculated using stoichiometric rules. However, some of the cations have more than one oxidation state. Therefore a choice must be made in advance of the measurement, as it is associated with the choice of the used standard for the WDS-

measurements. These standards were selected carefully to obtain reliable measurements of the compositions of the quenched samples. The oxygen content of the slag phase and spinel particles was not measured directly; but the oxidation state of each element was selected a priori. Although both $\mathrm{Fe}^{2+}$ and $\mathrm{Fe}^{3+}$ can be present, for the sake of clarity, only ' $\mathrm{FeO}^{\prime}$ ' was selected to be present in both the slag phase and spinel phase, similarly to Scheunis et al. ${ }^{28}$. The composition of the copper alloy droplets was measured in the elemental state.

\subsection{Set-up B: Study of the presence of copper droplets sticking to spinel solids as a function of time and slag height}

For the second experiment, two times $90 \mathrm{~g}$ of the target composition (Table 1) was weighed, mixed and transferred in two small $\mathrm{Al}_{2} \mathrm{O}_{3}$ crucibles $(60 \mathrm{ml}$, diameter $33 \mathrm{~mm}$, Crucible $\mathrm{A}$ and Crucible $\mathrm{B}$ ). The $\mathrm{Al}_{2} \mathrm{O}_{3}$ crucibles, surrounded by a protective SiC crucible, were simultaneously heated in an inductive furnace (Indutherm, MU3000) up to a temperature of $800^{\circ} \mathrm{C}$, while a protective $\mathrm{N}_{2}$ atmosphere was established above the slag. At $800^{\circ} \mathrm{C}$, the $\mathrm{N}_{2}$ atmosphere was replaced by $\mathrm{CO} /$ air mixture with volume ratio $1 / 2.44$, corresponding to an oxygen partial pressure $\left(p_{\mathrm{O}_{2}}\right)$ of $10^{-7}$ atm similar to the first experiment. Subsequently, the slag was heated 
until $1200^{\circ} \mathrm{C}$ and kept there 20 min in order to melt all components. $\mathrm{N}_{2}(60 \mathrm{l} / \mathrm{h})$ is bubbled through the slag in both crucibles in order to homogenize the slag during 5 min. Finally, crucible A was quenched $10 \mathrm{~min}$ and crucible B $20 \mathrm{~min}$ after the end of bubbling. In the present experiment, the entire crucibles were quenched in water, in which special attention was given to avoid tilting the crucibles. During the experiment, the slag was not given time to reach thermodynamic equilibrium before the start of the experiment.

Both crucibles were sawn lengthwise in two parts, which were subsequently sectioned in smaller parts using a diamond saw. These parts were embedded in epoxy resin, ground and polished using $9 \mu \mathrm{m}$ and $3 \mu \mathrm{m}$ diamond paste. The sample was analysed using LOM. The LOM pictures were used to determine the area \% of the entrained copper droplets and the spinel particles present in the slag by using the VHX software (VHX-2000E), as described for set-up A (section 2.1).

\section{Results}

\subsection{Experimental results set-up A}

An overview of the microstructures of the quenched slag samples taken from the upper slag layer at 5, 10, 20, 30, 60 and 90 min after bubbling is given in Figure 1 . Three phases can be distinguished in the microstructure: a liquid slag phase (SL, darker grey phase), spinel particles (SP, light grey phase) and copper alloy droplets (Cu-dr, black-yellow phase). To study the settling behaviour of the copper droplets, the area fraction of the copper droplets and spinel solids were determined. In each sample, 7 to 12 pictures have been analysed, from which an average value was deduced for each phase. No clear variations in the amount of spinel solids present in the upper layer $(2-3 \mathrm{~cm})$ are noticed. An average value of $12 \%$ is obtained for all samples. The area fraction of mechanically entrained copper alloy droplets, measured in the upper slag layer as a function of sedimentation time, is presented in Figure 2. A steep decrease of the amount of copper droplets entrained in the upper layer can be noted during the first 20 min of sedimentation. After $60 \mathrm{~min}$, all droplets settled down from the upper slag layer. This evolution is also clear in the LOM pictures presented in Figure 1.

In the slag samples after 5, 10, 20 and $30 \mathrm{~min}$, a significant amount of the entrained droplets sticks to the spinel solids present in the slag phase. Based on the LOM images, the percentage of entrained droplets sticking to spinel solids varies between $27 \%$ and $57 \%$ for the samples. It should however be mentioned that we study a two dimensional image of a three dimensional situation. Droplets might thus be in contact with a spinel solid, not visible in the 2D LOM image. Nevertheless, the 2D images show qualitatively that there is a considerable amount of sticking droplets present.

Figure 3 shows detailed images of sticking droplets for sedimentation times of 5, 10 and 20 min. From the enlarged microstructure obtained after 5 min of sedimentation (Figure $3-(a),(b)$ ) it appears that the spinel solids seem to have formed around the copper droplet, as indicated on Figure 3-(a) by the white circle. Similar observations are also made after 10 and $20 \mathrm{~min}$. Some droplets appear to stick only to a single spinel particle, while other droplets are surrounded 
completely by groups of spinel solids, as indicated on Figure 3-(e) by the white frames. A WDSmapping of a sticking copper alloy droplet after a sedimentation time of $5 \mathrm{~min}$, performed by EPMA, is shown in Figure 4. Based on the elemental mappings of $\mathrm{Cu}$ and $\mathrm{Pb}$ it is clear that the copper alloy droplets consist of a $\mathrm{Cu}$ rich-phase and a $\mathrm{Pb}$ rich-border, as indicated in Figure 4. It can be assumed that this phase separation occurred during quenching. Because of the large difference in melting temperatures and the rather low solubility of copper in liquid lead below $1000 \mathrm{~K}$, a phase separation between copper and lead could take place within the limited quenching time. The spinel solid consists out of two phases: an Al-rich spinel phase in the core, indicated as Al-Sp, and an Fe-rich spinel phase at the border, indicated as Fe-Sp. The attached copper droplets are thus always in contact with the Fe-rich spinel phase, and not with the Alrich spinel phase. Quantitative elemental analysis has been performed by WDS-EPMA and the results are summarized in Table 2 . The amount of spinel forming elements in the slag 'FeO' and $\mathrm{ZnO}$ decrease slightly with increasing sedimentation times, whereas the results for $\mathrm{Al}_{2} \mathrm{O}_{3}$ were more scattered and the amount of $\mathrm{PbO}$ slightly increased. The Fe-rich spinel phase contains higher amounts of $\mathrm{Zn}$ at longer sedimentation times of 60 and $90 \mathrm{~min}$.

\begin{tabular}{|c|c|c|c|c|c|c|c|c|c|c|c|}
\hline \multicolumn{8}{|c|}{ Slag - Sticking droplets } & \multicolumn{4}{|c|}{ Spinels - Sticking droplets } \\
\hline$w t \%$ & $\mathrm{Al}_{2} \mathrm{O}_{3}$ & 'FeO' & $\mathrm{Cu}_{2} \mathrm{O}$ & $\mathrm{CaO}$ & $\mathrm{ZnO}$ & $\mathrm{PbO}$ & $\mathrm{SiO}_{2}$ & $\mathrm{Al}_{2} \mathrm{O}_{3}$ & 'FeO' & $\mathrm{Cu}_{2} \mathrm{O}$ & $\mathrm{ZnO}$ \\
\hline $5 \mathrm{~min}$ & 8.1 & 20.5 & 1.1 & 8.4 & 6.2 & 30.4 & 25.6 & 18.3 & 67.1 & 0.1 & 11.7 \\
\hline $10 \mathrm{~min}$ & 7.5 & 20.2 & 1.0 & 8.6 & 6.1 & 29.2 & 27.2 & 16.5 & 66.8 & 0.1 & 10.6 \\
\hline $20 \mathrm{~min}$ & 8.2 & 20.4 & 1.3 & 8.2 & 6.1 & 31.4 & 25.4 & 16.2 & 67.9 & 0.1 & 11.1 \\
\hline $\begin{array}{l}30 \\
\min \end{array}$ & 7.4 & 17.5 & 1.5 & 8.4 & 5.6 & 34.6 & 26.6 & 16.2 & 68.7 & 0.2 & 11.4 \\
\hline $\begin{array}{l}60 \\
\min \end{array}$ & 9.3 & 17.0 & 1.7 & 7.9 & 4.8 & 35.3 & 24.9 & 15.1 & 64.7 & 0.9 & 20.3 \\
\hline $\begin{array}{l}90 \\
\min \end{array}$ & 8.9 & 14.3 & 2.2 & 8.5 & 4.2 & 36.4 & 24.8 & 16.0 & 65.3 & 0.3 & 16.5 \\
\hline
\end{tabular}

Table 2 EPMA-WDS analysis of slag and Fe-rich spinel phases after 5, 10, 20, 30, 60 and 90 min of sedimentation

Figure 5 shows the size distributions of the entrained copper droplets. An increase in sedimentation time leads to a decrease in average droplet size, as the larger droplets sink faster. After $5 \mathrm{~min}$ and $10 \mathrm{~min}$, droplets with a diameter larger than $50 \mu \mathrm{m}$ are present. For longer sedimentation times, the relative frequency of smaller droplets increases and almost all droplets are smaller than $15 \mu \mathrm{m}$ diameter.

\subsection{Experimental results set-up B}

Figure 6 gives an overview of the cross-sections of the crucibles quenched after 10 and 20 min sedimentation time. Every crucible contains a large copper nugget, localised at the bottom of the crucible, surrounded by slag. For each crucible, the slag phase is sub-divided in different horizontal layers, each located at a specific distance measured from the top of the copper droplet as indicated on Figure 6. For each zone, a representative LOM image is shown in Figure 6 . In these slag microstructures, three phases can be distinguished as expected: slag (SL), spinel 
solids (SP) and entrained copper droplets (Cu-dr). It can be observed that the amount of entrained copper droplets in the slag varies with height. As also observed in experiment $A$, spinel solids form around the copper droplets, as highlighted with the white arrows in Figure 7.

The area fractions covered by the copper droplets and spinel solids are determined for the different cross sections for every crucible. Figure 8 represents the area fraction of spinel particles and entrained copper droplets in the different slag layers as indicated on Figure 6 for crucible A (sedimentation time of $10 \mathrm{~min}$ ). The upper slag layer (slag layer (1) - in Figure 6) contains only a limited amount of very small copper droplets. Lower layers are characterized by an increasing amount of entrained copper droplets, and a maximum amount is present in slag layer (3), with a gradually decreasing amount below slag layer (3). The slag layers (6)-(7), next to the copper phase at the bottom of the crucible, contain a limited amount of entrained droplets. A similar evolution in the amount of the spinel solids present can be observed as well: a maximum area fraction of spinel solids is localised in slag layer (3), indicating the synchronization between both the amount of spinel solids and copper droplets. The size distribution of the entrained droplets is represented in Figure 9. It is noted that slag layers (3) and (4) contain the largest droplets, while the upper layers (1) and the lower layers (6) consist mainly of small copper droplets. Based on the LOM images, the fraction of droplets sticking at the spinel solids varies between $32 \%$ and $69 \%$. Similar as in section 3.1, it should be emphasized again that these values are indications only, as we observe a 2D image of a 3D system. Nevertheless, it indicates the importance of the phenomenon of sticking droplets within our system.

Figure 10 shows the area fraction of entrained copper droplets in crucible B, quenched after 20 min sedimentation. In contrast with the crucible quenched after $10 \mathrm{~min}$, the upper layer (layer $\left.\left(1^{\prime}\right)\right)$ does not contain entrained copper droplets anymore. It should also be mentioned, as is clear from Figure 6, that layer ( $\left.1^{\prime}\right)$ is positioned closer to the bottom of the crucible than layer (1). The same remark is valid for the other layers. Lower slag layers contain entrained copper droplets $\left(\left(2^{\prime}\right)-\left(5^{\prime}\right)\right)$, with a maximum area in slag layer $\left(3^{\prime}\right)$, as shown in Figure 10 . Similar to crucible A, lower layers $\left(\left(4^{\prime}\right)-\left(5^{\prime}\right)\right)$ contain less copper droplets. The area covered by spinel solids has a comparable profile, with also a maximum amount of spinel solids present in slag layer ( $\left.3^{\prime}\right)$. Similar to crucible A, crucible B displays the same synchronous presence of spinel solids and copper droplets. The size distribution of the entrained copper droplets for the different slag layers are summarized in Figure 11. Compared to the size distribution after 10 min of sedimentation, the difference in the size distribution for the different layers is less pronounced. Each slag layer contains a considerable amount of small droplets $(<15 \mu \mathrm{m})$, and a small fraction of larger droplets $(>15 \mu \mathrm{m})$. Hereby it can be noted that the largest droplets $(>20 \mu \mathrm{m})$ are mainly present in the lower slag layers $\left(4^{\prime}\right)$ and $\left(5^{\prime}\right)$, localised right above the underlying copper phase.

A considerable fraction of the entrained copper droplets present in the slag layers displays a sticking behaviour to spinel solids. Depending on the slag layer, the fractions vary between 33\% and $67 \%$. 


\section{Discussion}

\subsection{Thermodynamic stability of the sticking droplets}

In experiment $B$, it is observed from the LOM images that most layers contain mechanically entrained droplets, of which a significant fraction is attached to spinel particles. Moreover, the amount of spinel solids present is in proportion with the amount of copper droplets present for every crucible in experiment B (Figure 8 and Figure 10). This important link between the amount of spinel solids and the amount of entrained copper has already been pinpointed in literature. ${ }^{6}$,

${ }^{21,29}$ In view of primary copper production it was shown previously that higher magnetite contents resulted in higher amounts of mechanically entrained copper. ${ }^{21}$ According to Yannopolous $^{29}$, the effect of magnetite on copper losses can be attributed to a variety of factors such as an increase in the slag viscosity and the formation of a 'magnetite zone' between the slag and copper layer. The effect of copper droplets sticking on spinel particles was not considered so far in literature.

Droplets sticking to spinel particles are present in each slag layer in experiment B. This indicates that the attached droplets settle down together with their attached spinel particles. (Figure 6). However, if the copper droplets and spinel particles remain attached, this attachment should be energetically more stable than a non-attached copper droplet. Therefore, the situation of a nonattached copper droplet is compared with an attached copper droplet to a spinel solid in the slag using a simplified representation as shown in Figure 12. As described in section 3.1 and indicated on Figure $3-(\mathrm{e})$, some droplets are attached to one side of a spinel particle while other droplets are much more surrounded by spinel particles. Both cases are schematically represented in Figure 12.

$S$ represents the surface area of the copper droplet, $S_{1}$ represents the contact area between the copper droplet after attachment and $S_{2}$ represents the copper-slag area after attachment. With this, the assumption is made that the surface area of the copper droplet does not change after the attachment (i.e. $S=S_{1}+S_{2}$ ). Within the phenomenon of copper droplets sticking towards spinel solids in slags, the slag-copper $\left(\gamma_{\text {sl-cu }}\right)$, spinel-slag $\left(\gamma_{\text {sp-sl }}\right)$ and spinel-copper $\left(\gamma_{\text {sp-Cu }}\right)$ interfacial tension interact.

As it was assumed that sticking droplets probably decant together, it is a requisite from a thermodynamical point of view that the Gibbs free energy (surface energy) of the system before attachment is higher or equal than after attachment. This can be expressed as:

$S \cdot \gamma_{S l-C u}+S_{1} \cdot \gamma_{S p-S l} \geq S_{2} \cdot \gamma_{S l-C u}+S_{1} \cdot \gamma_{S p-C u}$

Equation ((1) can be re-arranged as follows:

$\left(S_{1}+S_{2}\right) \cdot \gamma_{S l-C u}+S_{1} \cdot \gamma_{S p-S l} \geq S_{2} \cdot \gamma_{S l-C u}+S_{1} \cdot \gamma_{S p-C u}$ 
$\gamma_{S l-C u}+\gamma_{S p-S l} \geq \gamma_{S p-C u}$

In order for the droplets to remain attached, it implies that equation ((3) should be valid.

\subsection{Origin of the sticking droplets}

It is seen in literature that the wettability of copper on spinel is not as good as the wettability of slags on a spinel substrate. Although it must be noted that the oxygen partial pressure plays a decisive role in the wettability ${ }^{30-32}$, it was found that under comparable conditions as the present ones, the slag presented a better wetting than $\mathrm{Cu}$ on spinel solids. The wetting between slag and spinel has been studied by Abdeyazdan et al. ${ }^{33}$ and Donald et al. ${ }^{34}$. Contact angles between $\mathrm{CaO}-\mathrm{Al}_{2} \mathrm{O}_{3}-\mathrm{SiO}_{2}-\mathrm{MgO}$ with $\mathrm{MgAl}_{2} \mathrm{O}_{4}{ }^{33}$ and fayalitic slag with $\mathrm{MgFe}_{2} \mathrm{O}_{4}, \mathrm{MgCr}_{2} \mathrm{O}_{4}$, $\mathrm{MgAl}_{2} \mathrm{O}_{4}{ }^{34}$ were determined to be around $20^{\circ}$. The contact angle between copper alloys and spinel substrates depends on the compositions of the spinel substrate and the oxygen level in the alloy and atmosphere and a distinction can be made between non-reactive and reactive systems. ${ }^{35}$ Nevertheless, to our knowledge, no experimental data have been published, showing comparable low contact angles. This might indicate that there is an energy barrier for copper droplets to overcome in order to attach to spinel solids present in the slag. To overcome this mechanical barrier and expel the slag film between the droplet and spinel, intensively stirring can be sufficient. In this view, the origin of the sticking droplets present in both types of experiments can be partially attributed to the bubbling of $\mathrm{N}_{2}$ through the slag.

On the other hand, the origin of the copper droplets sticking to spinel particles might also be explained by a chemical reaction. Within the two applied experimental methods to evaluate the evolution of copper droplet losses in a synthetic slag system, a clear interaction is observed between copper alloy droplets and spinel solids present in the slag. In both experiments a major part of the sticking droplets is surrounded by multiple spinel solids showing a very good wetting behaviour. In experiment A, sticking droplets are already present after 5 min of sedimentation. With this, the spinel solids fit perfectly to the (irregular) shape of the copper droplet for a major part of the sticking droplets, as shown in Figure 3. Similar observations are also noted in the slag phase in the quenched slag samples obtained after 10 and 20 min of sedimentation (experiment A). This observation is confirmed in experiment B, as illustrated by Figure 7. These findings are a strong indication that a possible origin of the sticking copper-alloy droplets towards spinel solids can be attributed to a chemical reaction and not to a collision due to intensive stirring. Based on this assumption, a mechanism is proposed that can explain the origin of the sticking copper droplets (and industrial systems), which is shown in Figure 13. For this, a slag system containing copper (under oxidized form or metallic form), with a slag composition that allows spinel formation (sub-liquidus), saturated in the spinel forming elements and which is out of thermodynamic equilibrium is assumed. Two alternative reaction pathways are proposed, depending on the local composition in the slag system, for which in both a chemical reaction is responsible for the origin of sticking copper droplets.

A first possible pathway starts from a metallic copper alloy droplet, containing spinel forming elements. In our synthetic system, these are most likely Cu-Fe-Zn-Pb droplets. Under locally oxidizing conditions, the alloying elements can oxidize, as illustrated in equation (4). 
$\left(2 \mathrm{Fe}, 2 \mathrm{Zn}, \frac{4}{3} \mathrm{Fe}, 2 \mathrm{~Pb}, 4 \mathrm{Cu}, 2 \mathrm{Cu}\right)+\mathrm{O}_{2} \rightarrow 2 \mathrm{FeO}, 2 \mathrm{ZnO}, \frac{2}{3} \mathrm{Fe}_{2} \mathrm{O}_{3}, 2 \mathrm{PbO}, 2 \mathrm{Cu} \mathrm{U}_{2} \mathrm{O}, 2 \mathrm{CuO}$

This equation and the following three equations were consciously kept as broad as possible to result in a general explanation for the phenomenon under investigation. Since, the presence and relative amounts of the spinel forming elements strongly depend on the local composition, we did not fix the stoichiometry in these reactions equations. The formed spinel-forming oxides can interact with other spinel forming oxides already present in the slag phase next to the droplet and form a spinel according to the following reaction:

$\left\{\mathrm{ZnO}, \mathrm{FeO}, \mathrm{CuO}, \mathrm{Fe}_{2} \mathrm{O}_{3}\right\}_{\text {oxidesfromdroplet }}+\left\{\mathrm{ZnO}, \mathrm{FeO}, \mathrm{CuO}, \mathrm{Fe}_{2} \mathrm{O}_{3}, \mathrm{Al}_{2} \mathrm{O}_{3}\right\}_{\text {oxidesslag }}$

$\rightarrow\left(\mathrm{Zn}^{2+} \mathrm{Fe}^{2+} \mathrm{Cu}^{2+}\right)\left(\mathrm{Al}^{3+} \mathrm{Fe}^{3+}\right)_{2} \mathrm{O}_{4}$

Consequently, the resulting solid forms next to the copper droplet. As stated in section 3.1, the spinel solids sticking to copper droplets consist mainly out of Fe (Table 2), supporting this reaction mechanism where the spinel forming elements are partially originating from the copper alloy droplet. A small fraction of copper might be oxidized and also incorporated in the spinel structure, as confirmed in the elemental analyses.

A second possible way starts from an oxide phase present in the system and containing $\mathrm{Cu}_{2} \mathrm{O}$, $\mathrm{FeO}, \mathrm{ZnO}$ and $\mathrm{Al}_{2} \mathrm{O}_{3}$. In this situation, the systems will evolve towards thermodynamically more stable oxides, implying that $\mathrm{FeO}$ will be oxidized towards $\mathrm{Fe}_{2} \mathrm{O}_{3}$, combined simultaneously with the reduction of $\mathrm{Cu}_{2} \mathrm{O}$ towards $\mathrm{Cu}$. The formed $\mathrm{Fe}_{2} \mathrm{O}_{3}$, which is an intermediate compound, will directly react with other spinel-forming components present in the slag. This can be written as indicated in equation (6) and (7):

$$
\begin{aligned}
& \mathrm{Cu}_{2} \mathrm{O}+2 \mathrm{FeO} \rightarrow 2 \mathrm{Cu}+\mathrm{Fe}_{2} \mathrm{O}_{3 \text { redox }} \\
& \mathrm{Fe}_{2} \mathrm{O}_{3 \text { redox }}+\left\{\mathrm{ZnO}, \mathrm{FeO}, \mathrm{CuO}, \mathrm{Fe}_{2} \mathrm{O}_{3}, \mathrm{Al}_{2} \mathrm{O}_{3}\right\}_{\text {oxidesslag }} \\
& \rightarrow\left(\mathrm{Zn}^{2+} \mathrm{Fe}^{2+} \mathrm{Cu}^{2+}\right)\left(\mathrm{Al}^{3+} \mathrm{Fe}^{3+}\right)_{2} \mathrm{O}_{4}
\end{aligned}
$$

In this reaction scheme, the copper droplets and spinel solids are formed on the same location, which might also imply that a small fraction of Cu-oxide can be incorporated in the spinel structure. In literature concerning primary copper production, a similar reaction has been described where cuprous oxide may react with ferrous oxide by ${ }^{21,24,36}$ :

$$
\mathrm{Cu}_{2} \mathrm{O}+3 \mathrm{FeO} \leftrightarrow 2 \mathrm{Cu}+\mathrm{Fe}_{3} \mathrm{O}_{4}
$$

For both proposed mechanisms, the reaction kinetics for the formation of spinel solids with in the slag plays an essential role. Nightingale and Monaghan ${ }^{37}$ studied these kinetics during the dissolution of $\mathrm{MgO}$ and simultaneous formation of $\mathrm{MgAl}_{2} \mathrm{O}_{4}$ spinel solids in a slag containing $\mathrm{CaO}, \mathrm{Al}_{2} \mathrm{O}_{3}$ and $\mathrm{SiO}_{2}$. They observed the formation of spinel crystals within seconds after the submersion of $\mathrm{MgO}$ in the slag. Scheunis et al. ${ }^{28}$ investigated the interaction between magnesiachromite refractories and a spinel saturated PbO non-ferrous slag. The formation of a new 
$(\mathrm{Mg}, \mathrm{Fe})(\mathrm{Al}, \mathrm{Fe}, \mathrm{Cr})_{2} \mathrm{O}_{4}$ spinel layer at a growth rate of $290.5 \mu \mathrm{m}^{2} / \mathrm{h}$ was observed. As noted by Scheunis et al., this growth rate appeared to be 50 times larger than other literature values for the $\mathrm{MgAl}_{2} \mathrm{O}_{4}$ spinel growth rate. ${ }^{28,37}$ The presence of magnetite was argued to play a key role in this higher growth rate. The cations in magnetite are characterised with an increased mobility, which serves as a possible explanation for the higher growth rate. ${ }^{28,38,39}$ Consequently, all cations have an increased mobility, which serves as a possible explanation for the higher growth rate. ${ }^{28}$ In the present work, the spinel layers/particles that form around the copper droplets are Fe-rich and the spinel solids can be considered as partially consisting of magnetite. Therefore, the abovementioned theory on the fast growth kinetics of magnetite can be extrapolated to the present work.

The above mentioned reaction scheme (Figure 13) offers a possible explanation for the origin copper droplet losses in industrial processes besides bubbling. In this respect, it should also be noted that copper is added to the system in a variety of forms, which also implies that several routes causing the interaction between the copper droplets and spinel particles might be possible. It is assumed that the sticking droplets find their origin in a kinetic effect, happening when the system evolves towards equilibrium.

\subsection{Sedimentation characteristics of sticking and non-sticking droplets}

As stated in the previous section, it can be assumed that the sticking droplets remain attached and thus settle down as one copper droplet-spinel entity. To define how this attachment affect the settling behaviour itself, a model is developed to estimate the influence of the droplet / spinel interaction on the sedimentation behaviour of the copper droplets, i.e. the settling rate of copper droplets. For this purpose, an adapted form of the Stokes equation is used, namely the Hadamard-Rybczynski formula: ${ }^{4,40}$

$u=\frac{g\left(\rho_{C u}-\rho_{s}\right) d^{2}}{12 \eta_{s}}$

where $u=$ settling rate $(\mathrm{m} / \mathrm{s}), \rho_{C u}$ is the density of the copper alloy droplets $\left(\mathrm{kg} / \mathrm{m}^{3}\right), \rho_{s}$ is the density of the slag $\left(\mathrm{kg} / \mathrm{m}^{3}\right), d$ is the diameter of the copper droplets $(\mathrm{m})$ and $\eta_{s}$ is the slag viscosity (Pa.s). The viscosity of the slag, containing spinel particles, can be estimated using the Einstein-Roscoe equation: ${ }^{41}$

$$
\eta_{s}=\eta_{0}(1-a f)^{-n}
$$

Where ' $\eta_{s}$ ' is the viscosity of liquid melt with solid particles (Pa.s), ' $\eta_{0}$ ' is the viscosity of the liquid without solid particles (Pa.s), ' $f$ is the volume fraction of solid particles in the melt, ' $a$ ' is a constant of which the reciprocal (1/a) can be interpreted as the maximum amount of solid that the liquid phase can accommodate when the viscosity reaches infinity and ' $n$ ' is a constant related to the particle shape. 
Based on experimental work of Wright et al. ${ }^{42}$, who investigated the influence of the addition of spinel particles of different sizes to $\mathrm{CaO}-\mathrm{MgO}-\mathrm{Al}_{2} \mathrm{O}_{3}-\mathrm{SiO}_{2}$ slags, $n=2.5$ and $a=2.6$ are chosen. The viscosity of the slag without solid particles is estimated using the viscosity module in FactSage, using the composition of the slag phase, determined after 5 min (Table 2). The fraction of spinel particles in the slag system is estimated to be 0.12 , based on the area of spinel particles in the slag found in experiment $A$ (section 3.1).

Based on these assumptions, a viscosity of 0.715 Pa.s is found and is to be used for all calculations to estimate the settling rate.

An additive method is used to estimate the density of the slag and Fe-rich spinel particles, in which the molar volume can be calculated based on equations:

$$
\begin{aligned}
& V=\frac{\sum_{i=1}^{n} M_{i} x_{i}}{\rho} \\
& V=\sum_{i=1}^{n} x_{i} V_{i}^{m}
\end{aligned}
$$

with $M_{i}$ the molecular weight (g/mole), $x_{i}$ the mole fraction and $V_{i}^{m}$ the partial molar The subscript ' $i$ ' denotes the various oxide constituents of the slag or spinel. The partial molar volume is assumed to be equal to the molar volume of the pure component. ${ }^{43}$ The compositions of the slag and Fe-rich spinel particles obtained from the quenching sample after 5 min sedimentation time in experiment A are used (exp A - Table 2), and give densities of 4528 $\mathrm{kg} / \mathrm{m}^{3}$ and $5082 \mathrm{~kg} / \mathrm{m}^{3}$ for slag and spinel particles respectively. Pure entrained copper droplets are supposed in the calculations.

For the calculations, the spinel solid and the attached copper droplet are considered as one settling 'Cu-droplet - spinel' entity. Three different types of conditions are under evaluation, based on the micro-structures described above and as shown in Table 3: (1) very small copper droplets embedded in a large spinel structure; (2) droplets attached to spinel solids with both having a similar size and (3) large copper droplets which are attached to a small spinel structure. Volume fractions of spinel and copper are summarized in Table 3 and used to calculate the 'average' density of the copper-spinel conglomerate. The densities of the copper-spinel conglomerates all have a density higher than the slag density, but lower than the metallic copper phase, which implies that the copper-spinel conglomerates do not settle down completely into the underlying copper phase. 


\section{Condition 1}

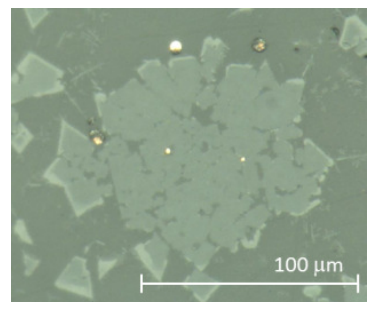

Vol \% spinel / Vol \% Cu 90/10

Density $\left(\mathrm{kg} / \mathrm{m}^{3}\right)$
5364.4
Condition 2

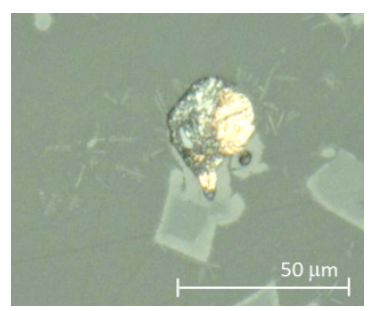

$50 / 50$

6490.5
Condition 3

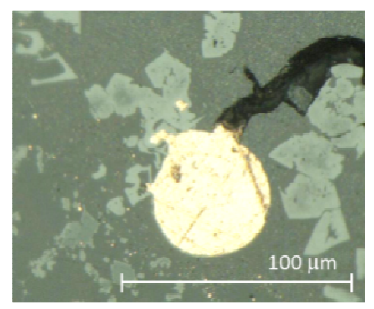

$10 / 90$

7616.5

Table 3 Overview of the three conditions of Cu droplets sticking to spinel solids in the slag considered in the calculations. For all conditions, they are considered as one 'Cu-Spinel' entity. The vol\% of spinel and $\mathrm{Cu}$ are given in the table together with the resulting density of the 'CuSpinel' entity

The calculated sedimentation rates for the 'Cu-droplet - spinel' are shown in Figure 14. For completeness, also the sedimentation rates for single copper droplets are shown. Comparing these rates between the three conditions under evaluation, it can be observed that an increasing amount of the spinel decreases the settling rate. This trend was expected as a higher spinel fraction results in a lower average density of the 'Cu-droplet - spinel' entity, which has a direct impact on the settling rate, as seen in the Hadamard Rybckzinski formula (equation ((9)). Although the simulation is based on a number of simplifying assumptions, a nice correlation is observed between the calculated and experimental values. In experiment $A$, most droplets present in the upper slag layer $(3 \mathrm{~cm})$ settled down in the first $30 \mathrm{~min}$, indicating a sedimentation rate of about $1 \mathrm{~mm} / \mathrm{min}$. The calculated sedimentation rates, shown in Figure 14, display values in the order of this experimentally estimated value.

The influence of the phenomenon of the sticking of copper droplets to spinel particles on the settling rate of these 'sticking copper droplets' is investigated by comparison of the settling rate of a copper spinel entity and a single copper droplet, having a similar diameter as the copper droplet in the 'Cu-droplet - spinel' entity. Hereby we refer to this single copper droplet as the 'isolated' copper droplet. Each condition (Table 3)) has to be considered separately as the size of the 'isolated' copper droplet depends on the condition. The settling rate of a 'Cu-droplet spinel' entity with a size of $100 \mu \mathrm{m}$ has been selected, on which the comparison is applied as indicated by the frame on Figure 14. The size of the 'isolated' droplet was determined separately for each situation: condition (1) - small entrained copper droplets of $10 \mu \mathrm{m}$; condition (2) - entrained copper droplet size of $40 \mu \mathrm{m}$; condition (3) - larger entrained copper droplet size of $90 \mu \mathrm{m}$. The comparison of the settling rate of the 'Cu-droplet - spinel' entity for each condition, assuming a size of $100 \mu \mathrm{m}$ and the settling rate corresponding 'isolated' droplet, is indicated on Figure 14 by the arrows. From this, it seems that the settling rate of the 'isolated' droplets is consistently lower in every situation then the 'Cu-droplet - spinel' entity. This is related to the smaller diameters of the 'isolated' copper droplets, which appear to have a 
prominent influence on the settling rate, despite the higher density difference between copper and slag compared to the 'Cu-droplet - spinel' entities and the slag. This is linked to the Hadamard-Rybczynski formula (equation ((9)), in which the settling rate is proportional with the density difference but proportional to the square of the diameter of the droplets

Figure 15 gives a schematic representation of the settling behaviour of sticking and non-sticking droplets in a slag phase towards an underlying copper phase. Picture (a) represents the initial stage of the slag-copper phase, in which sticking droplets of every situation are reflected. As the density of the copper droplets and the 'Cu-droplet - spinel' entities are higher than the slag density, both will settle down, as indicated with the arrows in picture (b) (Figure 15) Depending on the condition and the size of the droplets, different settling rates are expected, which is schematically represented by the size of the arrows.

The lower densities of the 'Cu-droplet - spinel' entities on the other hand have an important consequence. The copper droplets in 'Cu-droplet - spinel' entity might not be able to settle down to the underlying copper phase due to this lower apparent density of the 'Cu-droplet spinel' entity, which is lower compared to the density of the underlying copper phase itself. Hereby it is likely that the 'Cu-droplet - spinel' entities gather in the lower lying slag layers, right above the copper phase. This assumption is supported by the fact that in literature, the presence of a spinel-layer right above an underlying copper or matte phase has already been observed by Cardona et al. ${ }^{4}$ and Yannopoulos ${ }^{29}$. This is schematically shown in Figure $15-$ picture (c). Additionally copper droplets which are totally surrounded by spinel solids, especially in the situation (1), are hindered to coagulate with other copper droplets which are present in the slag system, hampering in this view also the further settling process.

Notwithstanding the fact that for the calculation of the settling rates of the attached 'Cu-droplet - spinel' entities a simplified approach of the complex phenomenon was used, the calculations clearly show that the phenomenon of attached droplets hampers the settling process in a significant way. More important, they reveal a mechanism for the hindrance that is different from the one assumed. Comparison of the settling rate of the sticking copper droplets (the 'Cudroplet - spinel' entities) with the settling rate of the 'isolated' droplets namely shows that the phenomenon of sticking droplets does not cause the hindering of the sedimentation process by lowering the settling rate (the settling rate of an attached droplet is even slightly larger than that of a copper droplet on itself). Instead the calculations suggest that an important hindrance of the phenomenon of sticking droplets is due to the fact that the sticking copper droplets (the 'Cu-droplet - spinel' entities) are not able to settle down completely to the underlying metallic copper phase, since the average density of the copper droplet-spinel entity is lower than that of the copper alloy layer underneath the slag.

\section{Conclusion}

In this section the phenomenon of sticking copper alloy droplets to spinel solids in slags, hindering the sedimentation behaviour, is studied. Two complementary experiments, using a synthetic $\mathrm{PbO}-\mathrm{SiO}_{2}-\mathrm{FeO}-\mathrm{Al}_{2} \mathrm{O}_{3}-\mathrm{CaO}$ slag, have been performed. In a first experiment the influence of the sedimentation time on the sedimentation of the sticking and non-sticking 
copper alloy droplets is examined. In the second experiment, the presence of sticking and nonsticking copper alloy droplets is studied as a function of the height in the slag layer.

It is observed that the sticking droplets remain attached and settle down. However, as slag exhibits a better wetting than copper on spinel, an energy barrier should be overcome by the copper droplets to expel the slag layer. In this view, two different ways are proposed to explain the origin of the sticking copper droplets. Firstly, extensive stirring can be sufficient to induce the attachment. Secondly it was suggested that sticking droplets find their origin in a chemical reaction, happening when the system evolves towards equilibrium. A reaction scheme is proposed, including two possible pathways whereby the spinel solids form around the copper droplets or form together with the copper droplets, depending on the local conditions of the system.

A model to calculate the settling rates based on the Hadamard-Rybczynski formula is developed. Although the model is based on a number of simplifying assumptions, interesting insights are gained concerning the influence of the sticking interaction between spinel solids and copper droplets on the settling behaviour. The calculated settling rates are of the order of the experimentally obtained settling rate of $1 \mathrm{~mm} / \mathrm{min}$. It is noted that the attachment of the copper droplets to spinel particles hinders the complete sedimentation towards the underlying copper phase, since the average density of the 'Cu-droplet - spinel' entity is lower than that of the underlying copper. Additionally the presence of attached spinel particles can hinder the coagulation of smaller droplets, which also hinders the settling rate.

\section{Acknowledgements}

The authors wish to thank the agency for innovation by science and technology in Flanders (IWT, project 110541) and Umicore for its financial support. In particular Maurits van Camp, Luc Coeck, Saskia Bodvin, Kristel Van Ostaeyen, Eddy Boydens, Danny Leysen and the technical staff of Umicore R\&D are thanked for their support with the experiments and characterization. Chunwei Liu is thanked for the help with the calculations of the settling rates. Pieter L'Hoest is thanked for the help with the EPMA measurements.

\section{References}

1. R. Degel, H. Oterdoom, J. Kunze, A. Warczok, and G. Riveros: 'Latest results of the slag cleaning reactor for copper recovery and its potential for the PGM industry', Proc. Conf. Third international platinum conference 'Platinum in Transformation', Sun City, South Africa October 2008, The Southern African Institue of Mining and Metallurgy, Paper 7, 197-202.

2. I.-K. Suh, Y. Waseda, and A. Yazawa, High Temperature Materials and Processes, 1988, 8(1), 65-88.

3. J. L. Liow, M. Juusela, N. B. Gray, and I. D. Sutalo, Metallurgical and Materials

Transactions B-Process Metallurgy and Materials Processing Science, 2003, 34(6), 821-

832. 
4. N. Cardona, L. Hernandez, E. Araneda, and R. Parra: 'Evaluation of copper losses in the slag cleaning circuits from two Chilean smelters', Proc. Conf. Copper 2010, Hamburg, Germany June 2010, GMDB, Vol 7, 2637-2654.

5. N. Cardona, P. Coursol, P. J. Mackey, and R. Parra, Canadian Metallurgical Quarterly, 2011, 50(4), 318-329.

6. I. Imris, M. Sanchez, and G. Achurra: 'Copper losses to slags obtained from the EI Teniente process', Proc. 7th Int. Conf. on molten slags, fluxes and salts., Johannesburg, South Africa January 2004, 177-182.

7. R. Sridhar, J. Toguri, and S. Simeonov, Metallurgical and Materials transactions B, 1997, 28(2), 191-200.

8. S. W. Ip and J. M. Toguri, Metallurgical Transactions B-Process Metallurgy, 1992, 23(3), 303-311.

9. R. Minto and W. G. Davenport, Canadian Mining and Metallurgical Bulletin, 1972, 65(720), C36-42.

10. H. C. Maru, D. T. Wasan, and R. C. Kintner, Chemical Engineering Science, 1971, 26(10), 1615-1628.

11. L. Andrews: 'Base metal losses to furnace slag during processing of platinum-bearing concentrates', PhD thesis, University of Pretoria, Pretoria, 2008.

12. A. Malfliet, S. Lotfian, L. Scheunis, V. Petkov, L. Pandelaers, P. T. Jones, and B. Blanpain, Journal of the European Ceramic Society, 2014, 34(3), 849-876.

13. E. De Wilde, I. Bellemans, M. Campforts, A. Khaliq, K. Vanmeensel, D. Seveno, M. Guo, M. Rhamdhani, G. A. Brooks, B. Blanpain, N. Moelans, and K. Verbeken, Materials science and technology 2015, In press

14. H. Kim, B. Ozturk, and R. J. Fruehan, Isij International, 1998, 38(5), 430-439.

15. J. Savolainen, T. Fabritius, and O. Mattila, Isij International, 2009, 49(1), 29-36.

16. D. Poggi, R. Minto, and W. Davenpor, Journal of Metals, 1969, 21(11), 40-\&.

17. G. Akdogan and R. H. Eric: 'Physical modelling of slag-metal dispersion', VII International Conference on Molten Slags Fluxes and Salts,, The South African Institute of Mining and Metallurgy, 2004, 671-678.

18. I. Bellemans, N. Moelans, and K. Verbeken, Computational Materials Science, 2015, 108B, 348-357.

19. P. F. Tan, Jom, 2011, 63(12), 51-57.

20. S. Pirker, Steel Research International, 2010, 81(8), 623-629.

21. I. Imris: 'Copper losses in copper smelting slags', Metallurgical and Materials Processing: Principles and Technologies, Vol 1: Materials Processing Fundamentals and New Technologies, 2003.

22. Y. Takeda: 'Thermodynamic evaluation of copper loss in slag equilibrated with matte', Metallurgical and Materials Processing: Principles and Technologies, Vol 1: Materials Processing Fundamentals and New Technologies, 2003, 341-357.

23. K. Genevski and V. Stefanova, Canadian Metallurgical Quarterly, 2008, 47(1), 51-58.

24. H. Jalkanen, J. Vehvilainen, and J. Poijarvi, Scandinavian Journal of Metallurgy, 2003, 32(2), 65-70.

25. J. E. and H. P.C., Mineral Processing and Extractive Metallurgy, 2008, 117(1), 1-17.

26. T. Hidayat, P. C. Hayes, and E. Jak, Metall. Mater. Trans. B., 2011, 43, 14-26. 
27. T. Hidayat, H. M. Henao, P. C. Hayes, and E. Jak, Metall. Mater. Trans. B., 2012, 43, 10341045.

28. L. Scheunis, M. Campforts, P. T. Jones, B. Blanpain, and A. Malfliet, Journal of the European Ceramic Society, 2015, 35(1), 347-355.

29. Yannopoulos.Jc, Canadian Metallurgical Quarterly, 1971, 10(4), 291-\&.

30. A. C. D. Chaklader, A. M. Armstrong, and S. K. Misra, Journal of the American Ceramic Society, 1968, 51(11), 630-633.

31. M. Makipaa and P. Taskinen, Scandinavian Journal of Metallurgy, 1980, 9(6), 273-281.

32. C. A. Gonzalez, W. F. Caley, and R. A. L. Drew, Metallurgical and Materials Transactions B-Process Metallurgy and Materials Processing Science, 2007, 38(2), 167-174.

33. H. Abdeyazdan, N. Dogan, M. A. Rhamdhani, M. Chapman, and B. Monaghan, Metallurgical and Materials Transactions B, 2014, 46(1), 208-219.

34. J. R. Donald, J. M. Toguri, and C. Doyle, Metallurgical and Materials Transactions BProcess Metallurgy and Materials Processing Science, 1998, 29(2), 317-323.

35. N. Eustathopoulos, M. G. Nicholas, and B. Drevet, Wettability at high temperatures in Pergamon materials series R. W. C. frs, Editor. 1999, Pergamon. p. 420.

36. I. Imris, M. Sanchez, and G. Achurra: 'Copper losses to slags obtained from the EI Teniente process', VII international conference on molten slags Fluxes and Salts, 2004.

37. S. A. Nightingale and B. J. Monaghan, Metallurgical and Materials Transactions B-Process Metallurgy and Materials Processing Science, 2008, 39(5), 643-648.

38. R. Dieckmann and H. Schmalzried, Berichte Der Bunsen-Gesellschaft-Physical Chemistry Chemical Physics, 1977, 81(4), 414-419.

39. R. Dieckmann and H. Schmalzried, Berichte Der Bunsen-Gesellschaft-Physical Chemistry Chemical Physics, 1977, 81(3), 344-347.

40. R. Clift, J. R. Grace, and M. E. Weber: 'Bubbles, Drops and Particles'; 1978, Dover PUBN Incorporated.

41. S. H. Seok, S. M. Jung, Y. S. Lee, and D. J. Min, Isij International, 2007, 47(8), 1090-1096.

42. S. Wright, L. Zhang, S. Sun, and S. Jahanshahi, Metallurgical and Materials Transactions B-Process Metallurgy and Materials Processing Science, 2000, 31(1), 97-104.

43. M. A. Nkohla: 'Characterization of ferrochrome smelter slag and it's implications in metal accounting', PhD thesis, Cape Peninsula University of Technology 2006.

\section{Figure captions}

Figure 1 Representative LOM pictures of the upper slag layer at 5, 10, 20, 30, 60 and 90 min after bubbling. (SL = slag, $\mathrm{SP}=$ spinel solids, $\mathrm{Cu}-\mathrm{dr}=$ copper alloy droplets)

Figure 2 Evolution of the area fraction of entrained copper droplets in the microstructure after $5,10,20,30,60$ and 90 min sedimentation

Figure 3 LOM (upper pictures) and BSE (lower pictures) images of droplets attached to spinel solids in the slag phase after 5, 10 and 20 min of sedimentation (Fe-SP = Fe-rich spinel phase, Al$\mathrm{SP}=$ Al-rich spinel phase) 
Figure 4 EPMA-WDS mapping of the interaction between a copper alloy droplet and a spinel substrate. The copper alloy droplets consist out of a $\mathrm{Cu}$-core and a $\mathrm{Pb}$-border; two types of spinel phases are present: an Fe-rich spinel phase (Fe-SP) and an Al-rich spinel phase (Al-SP)

Figure 5 Size distribution of entrained copper droplets in the upper slag layer after 5, 10, 20 and 30 min of sedimentation

Figure 6 Subdivision of the quenched crucibles after sedimentation times of 10 min (crucible A) and $20 \mathrm{~min}$ (crucible B) in different zones, indicated on the photographs of the crucible representative LOM images of the microstructures of each slag zone. (SP = spinel, SL = slag, Cu$\mathrm{dr}=\mathrm{Cu}$-alloy droplet)

Figure 7 Detailed LOM images of copper alloy droplets attached to spinel particles in exp B crucible $A$, indicated with the arrows ( $S P=$ spinel, $S L=$ slag)

Figure 8 Distribution area fraction (\%) of entrained copper droplets (left) and spinel solids (right) in each slag layer in the crucible quenched after 10 min sedimentation (exp B)

Figure 9 Size distribution entrained copper droplets in crucible $A$, quenched after 10 min sedimentation (exp B)

Figure 10 Distribution area fraction (in \%) of entrained copper droplets (left) and spinel solids (right) in each slag layer in crucible B quenched after 20 min sedimentation (exp B)

Figure 11 Size distribution of mechanically entrained droplets in crucible B, quenched after 20 min sedimentation

Figure 12 Schematic representation of a copper droplet before and after attachment to a spinel solid in the slag phase. Two types of attachment are considered: the attachment one side of spinel solid, and droplets which are surrounded by spinel solids $(S=$ surface area copper droplet before attachment, $\mathrm{S}_{1}=$ contact area spinel and copper after attachment, $\mathrm{S}_{2}=$ contact area slag and copper after attachment)

Figure 13 Possible reaction scheme to explain the origin of copper droplets sticking to spinel particles, including two possible pathways are suggested

Figure 14 Calculated settling rate as a function of the size of the 'Cu-droplet - spinel' entity for each situation and pure copper. Additionally, the settling rate of a 'Cu-droplet - spinel' entity of $100 \mu \mathrm{m}$ is compared with the settling rate of an 'isolated' copper droplet, having a similar diameter as the copper droplet in the spinel entity, which is indicated by the arrows.

Figure 15 Schematic representation of settling behaviour of entrained copper droplets, both sticking and non-sticking to spinel particles : (a) Initial situation : a slag system containing spinel particles and entrained copper droplets, both sticking (for which each condition is represented), and non-sticking droplets (b) sedimentation of both the 'Cu-droplet - spinel' entities and the 'isolated' copper droplets, for which the 'isolated' copper droplets have a slower settling rate compared to the 'Cu-droplet - spinel' entities, which is reflected in the size of the arrows (c) gathering 'Cu-droplet - spinel' above the slag layer due to lower densities of the 'Cu-droplet spinel' entity then the copper phase. 


\section{Table captions}

Table 1 Target synthetic slag composition, chosen based on FactSage calculations

Table 2 EPMA-WDS analysis of slag and Fe-rich spinel phases after 5, 10, 20, 30, 60 and 90 min of sedimentation

Table 3 Overview of the three conditions of $\mathrm{Cu}$ droplets sticking to spinel solids in the slag considered in the calculations. For all conditions, they are considered as one 'Cu-Spinel' entity. The vol\% of spinel and $\mathrm{Cu}$ are given in the table together with the resulting density of the ' $\mathrm{Cu}$ Spinel' entity

\section{Figures}
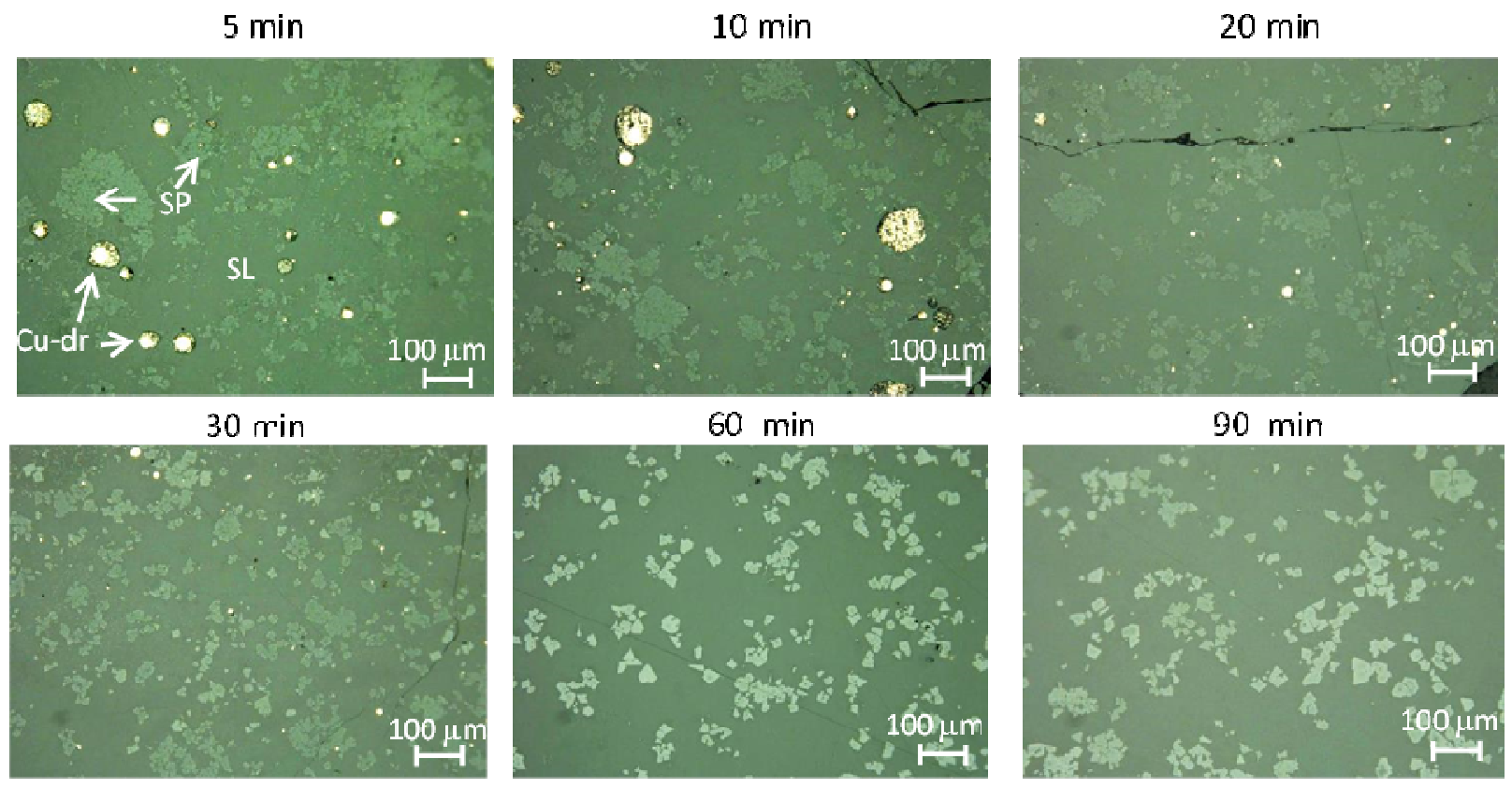

Figure 1 Representative LOM pictures of the upper slag layer at 5, 10, 20, 30, 60 and 90 min after bubbling. (SL = slag, $S P=$ spinel solids, $C u-d r=$ copper alloy droplets) 


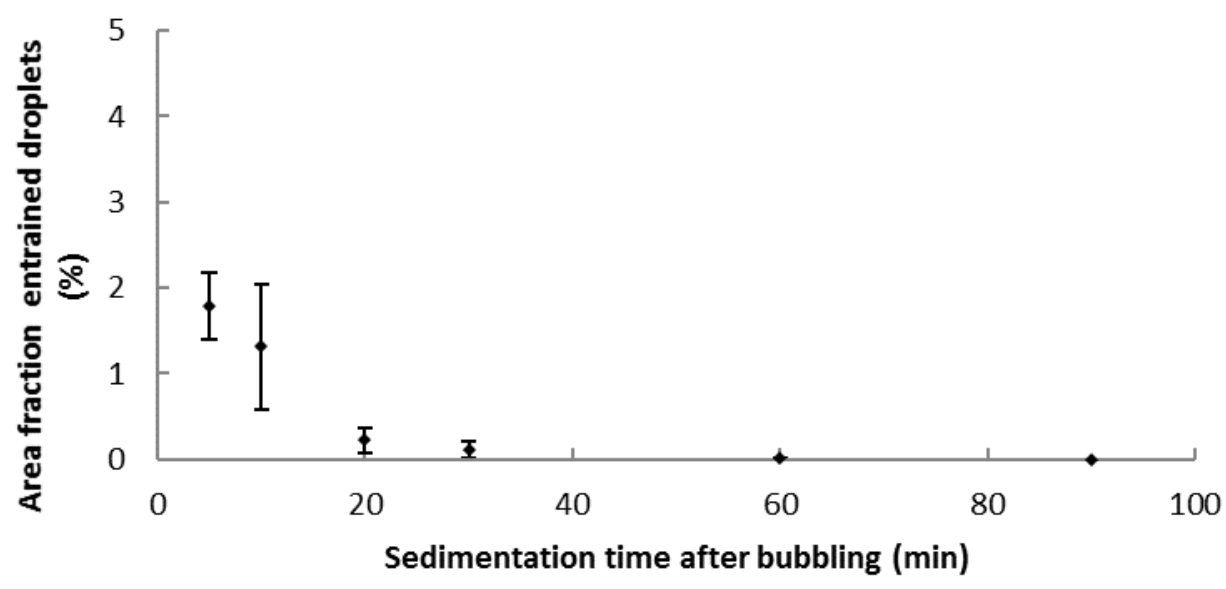

Figure 2 Evolution of the area fraction of entrained copper droplets in the microstructure after 5 , $10,20,30,60$ and 90 min sedimentation

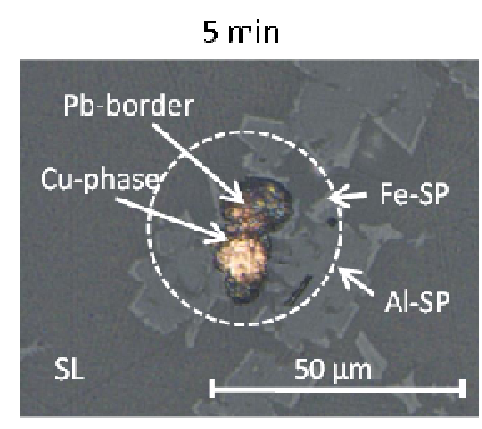

$(\mathrm{a})$

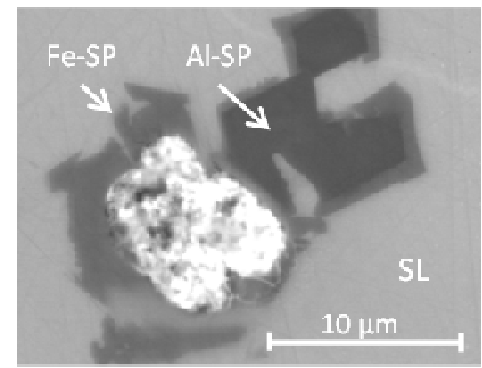

(b)

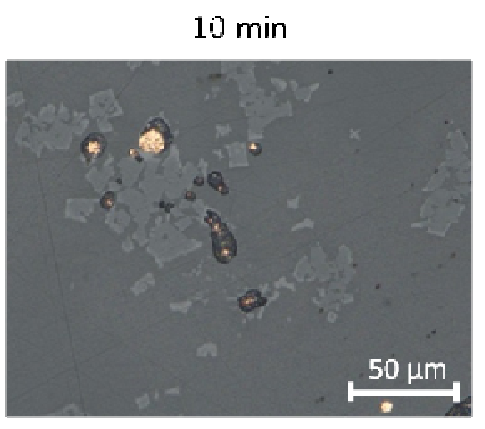

(c)

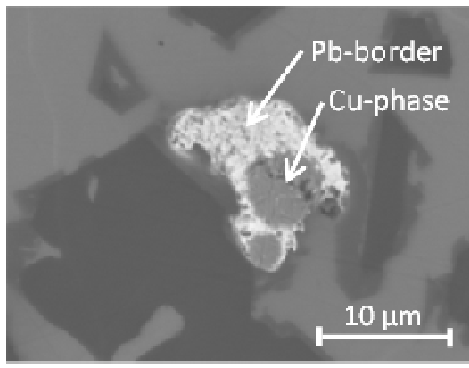

(d)

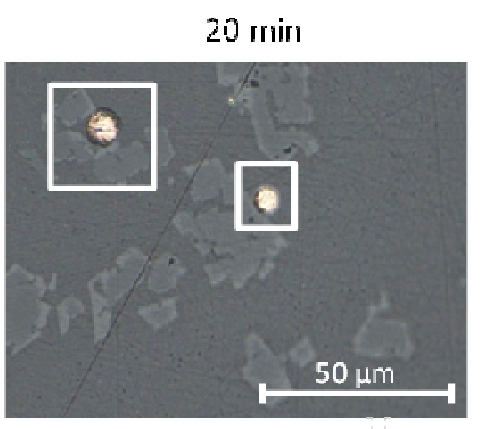

(e)

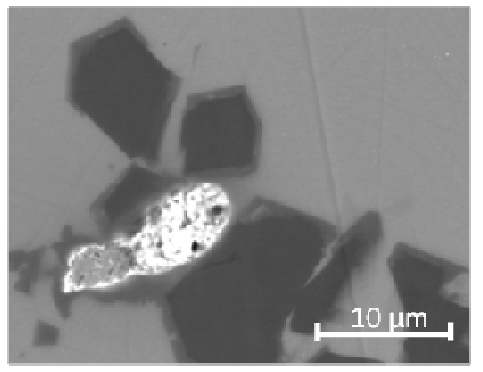

$\left(\mathrm{f}^{\prime}\right)$

Figure 3 LOM (upper pictures) and BSE (lower pictures) images of droplets attached to spinel solids in the slag phase after 5, 10 and 20 min of sedimentation (Fe-SP = Fe-rich spinel phase, Al$S P=$ Al-rich spinel phase) 

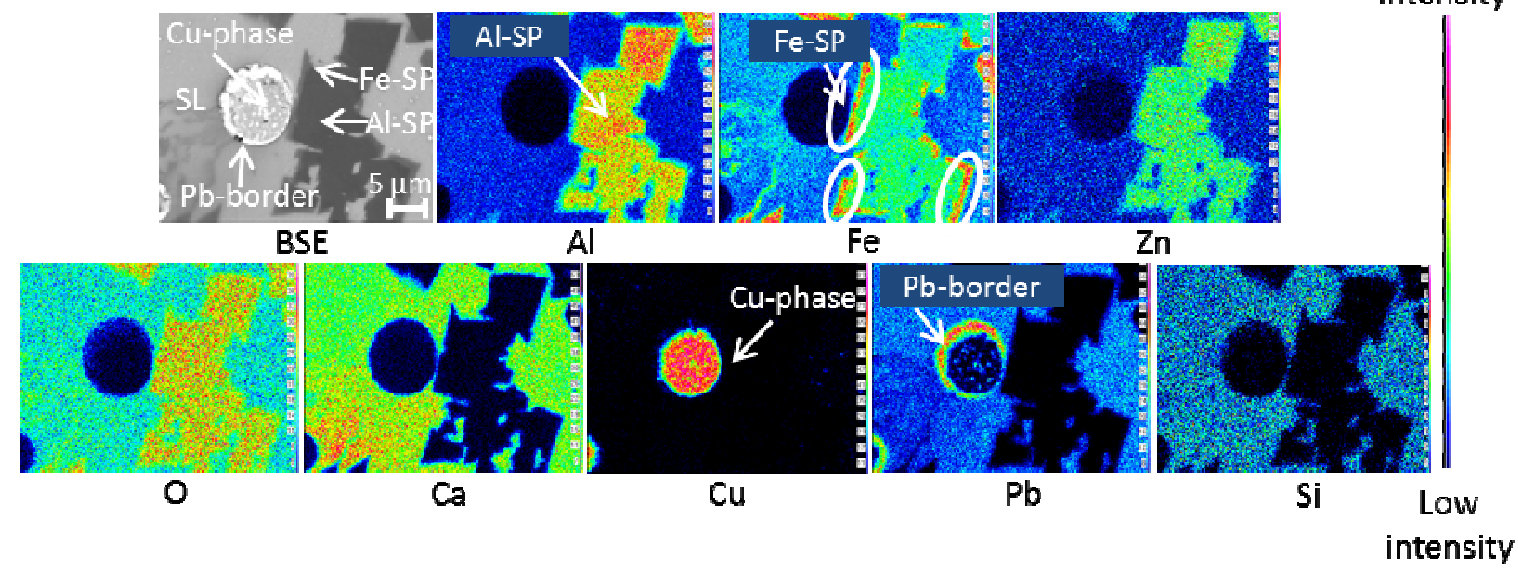

Figure 4 EPMA-WDS mapping of the interaction between a copper alloy droplet and a spinel substrate. The copper alloy droplets consist out of a $\mathrm{Cu}$-core and a Pb-border; two types of spinel phases are present: an Fe-rich spinel phase (Fe-SP) and an Al-rich spinel phase (AI-SP)

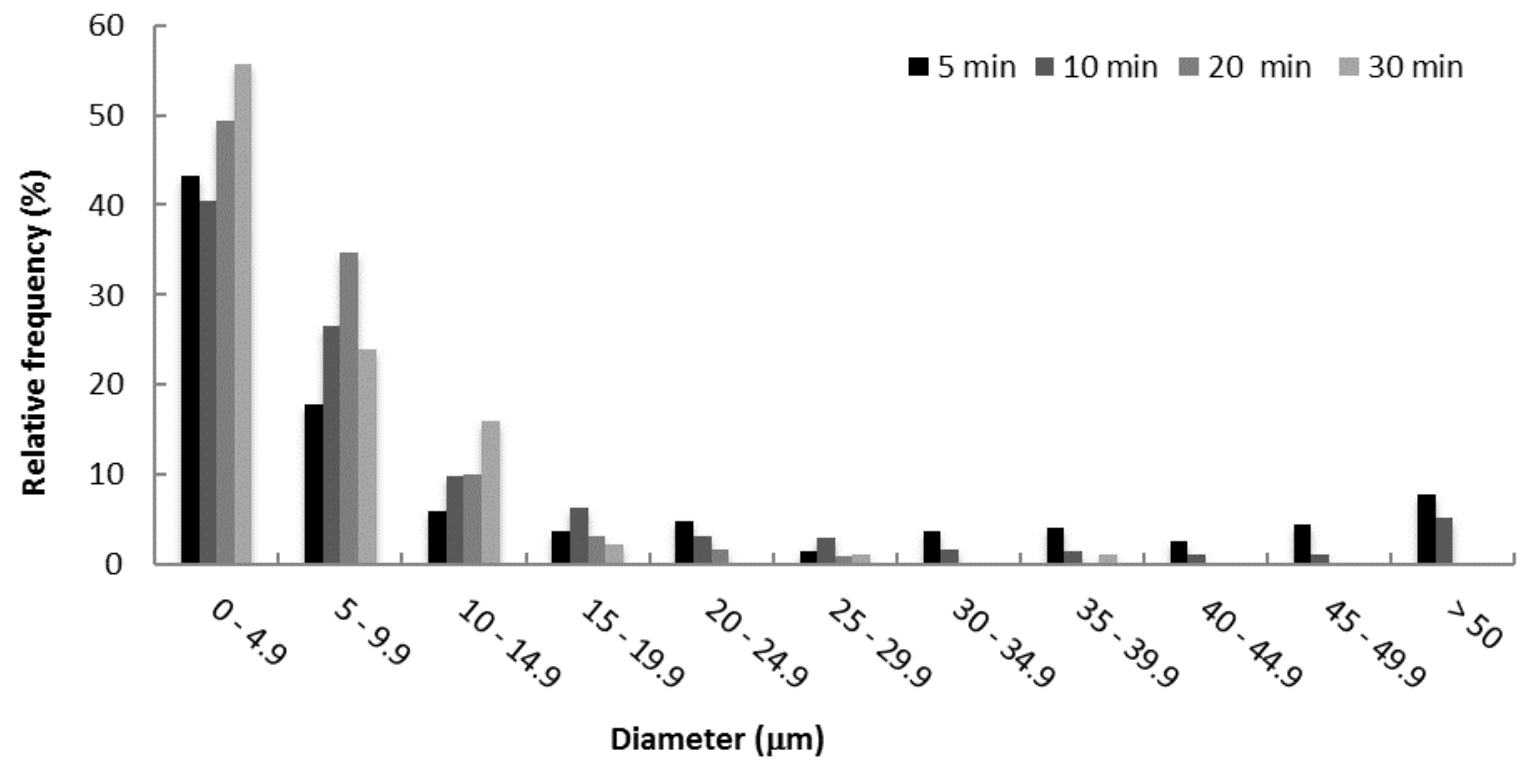

Figure 5 Size distribution of entrained copper droplets in the upper slag layer after 5, 10, 20 and 30 min of sedimentation 

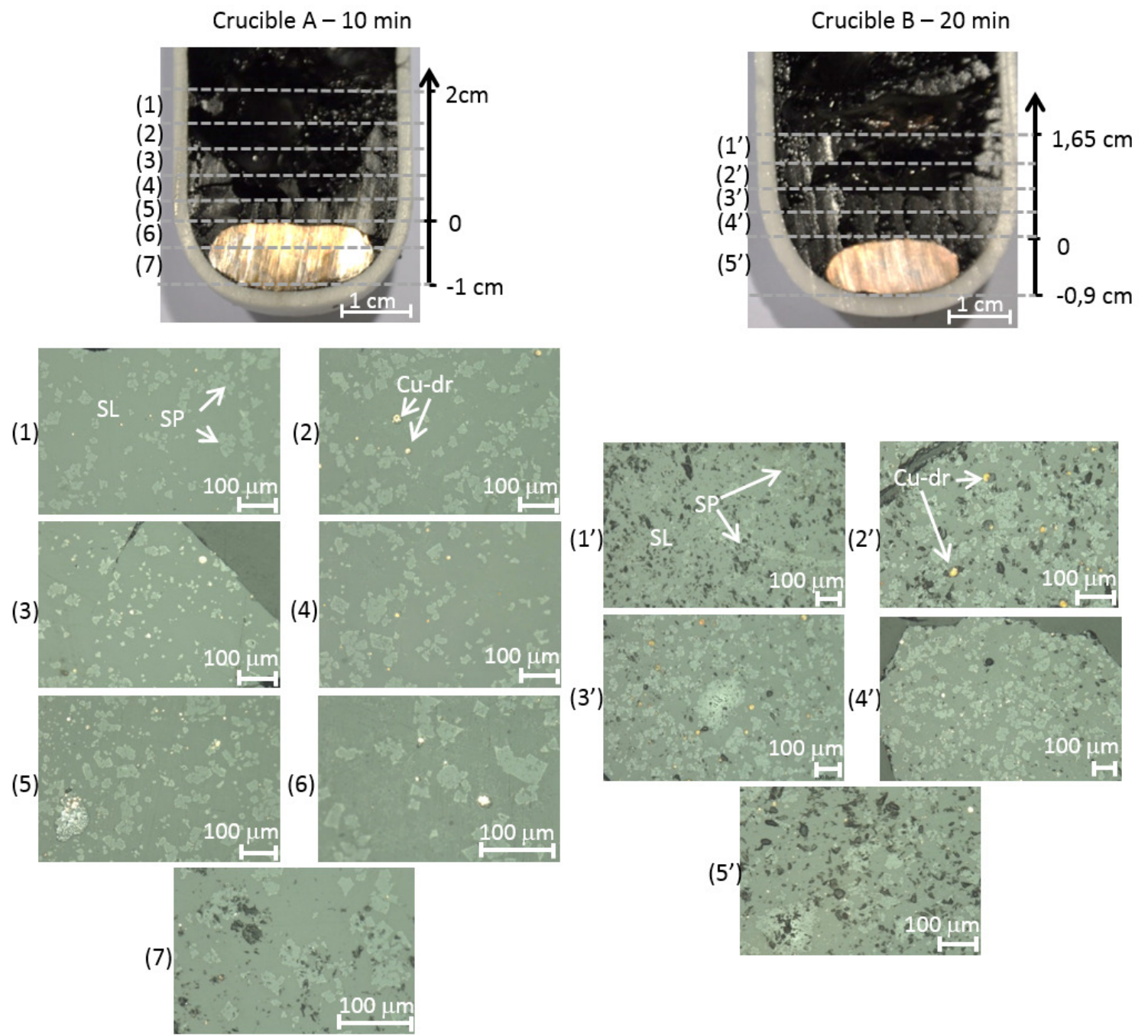

$\left(3^{\prime}\right)$
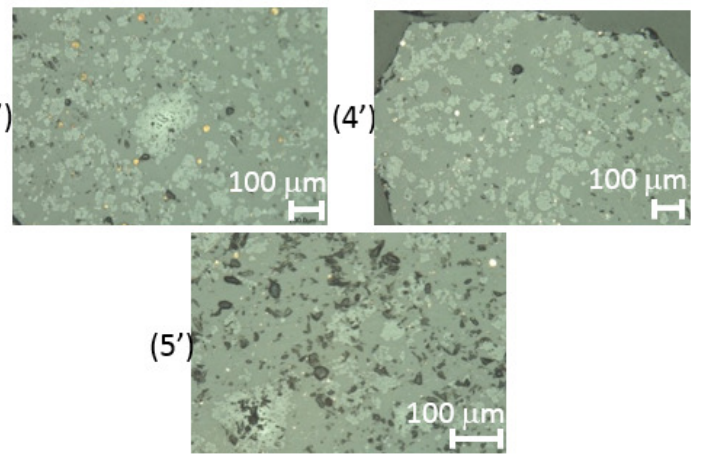

Figure 6 Subdivision of the quenched crucibles after sedimentation times of $10 \mathrm{~min}$ (crucible A) and 20 min (crucible B) in different zones, indicated on the photographs of the crucible representative LOM images of the microstructures of each slag zone. (SP = spinel, $S L=$ slag, $\mathrm{Cu}$ $d r=$ Cu-alloy droplet)
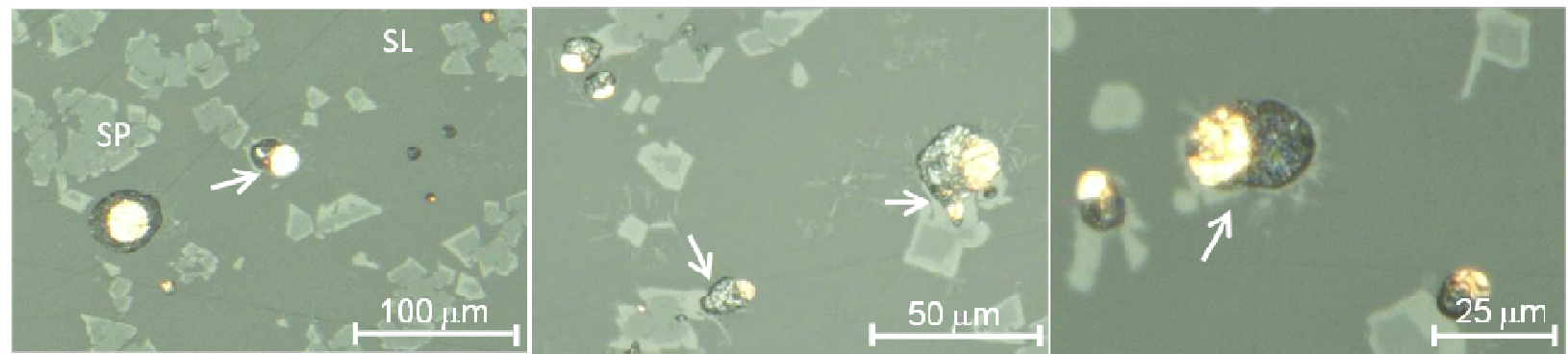

Figure 7 Detailed LOM images of copper alloy droplets attached to spinel particles in exp Bcrucible $A$, indicated with the arrows (SP = spinel, $S L=$ slag) 

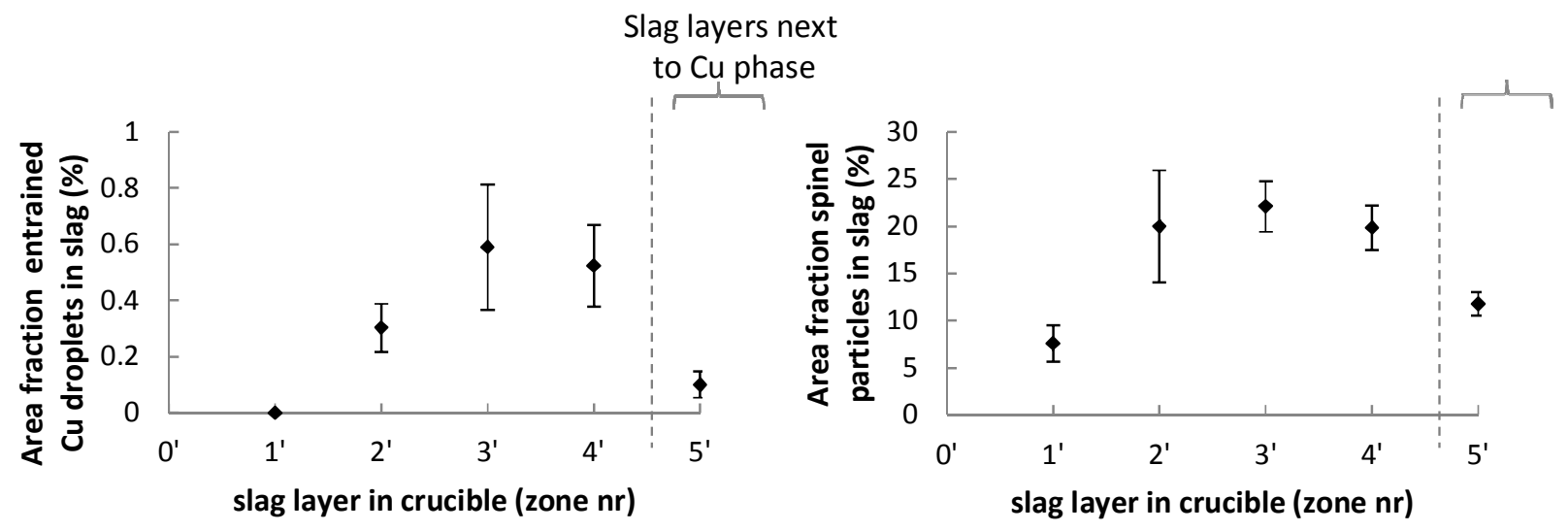

Figure 8 Distribution area fraction (\%) of entrained copper droplets (left) and spinel solids (right) in each slag layer in the crucible quenched after 10 min sedimentation (exp B)

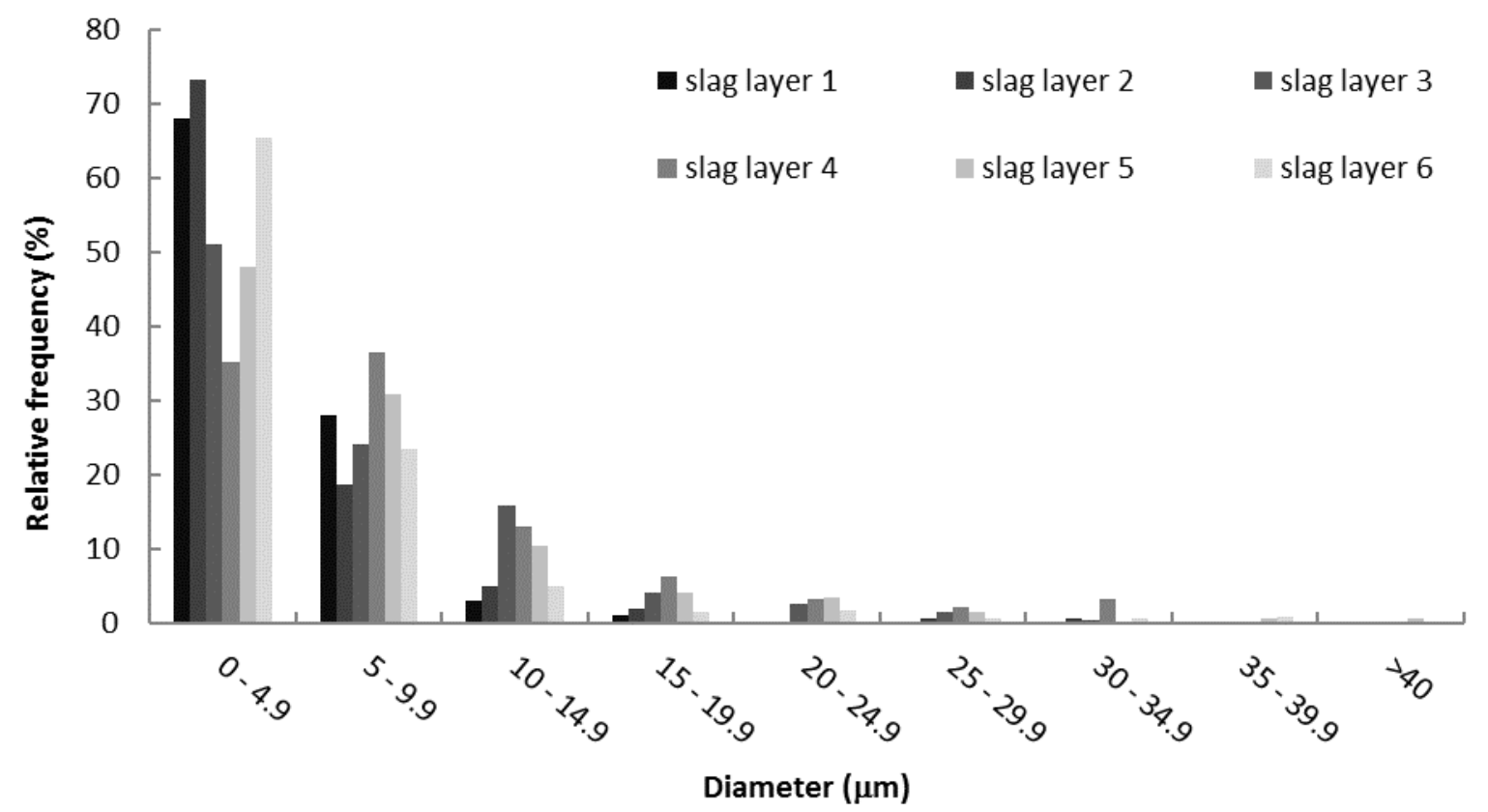

Figure 9 Size distribution entrained copper droplets in crucible A, quenched after 10 min sedimentation (exp B) 

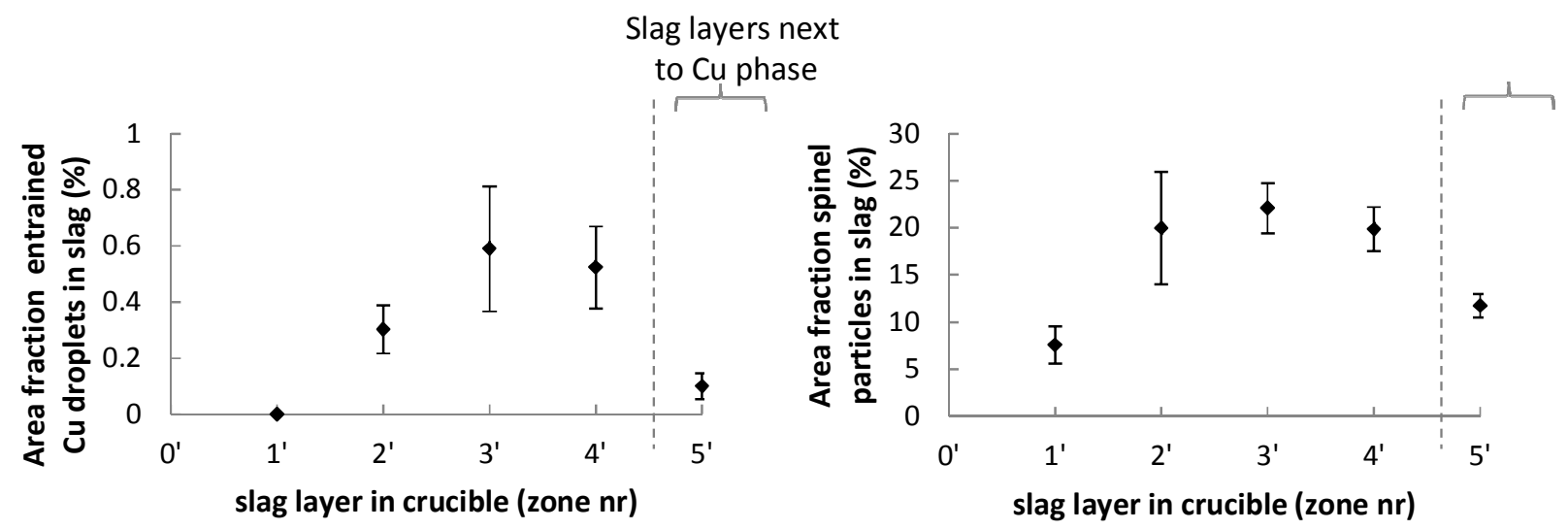

Figure 10 Distribution area fraction (in \%) of entrained copper droplets (left) and spinel solids (right) in each slag layer in crucible B quenched after 20 min sedimentation (exp B)

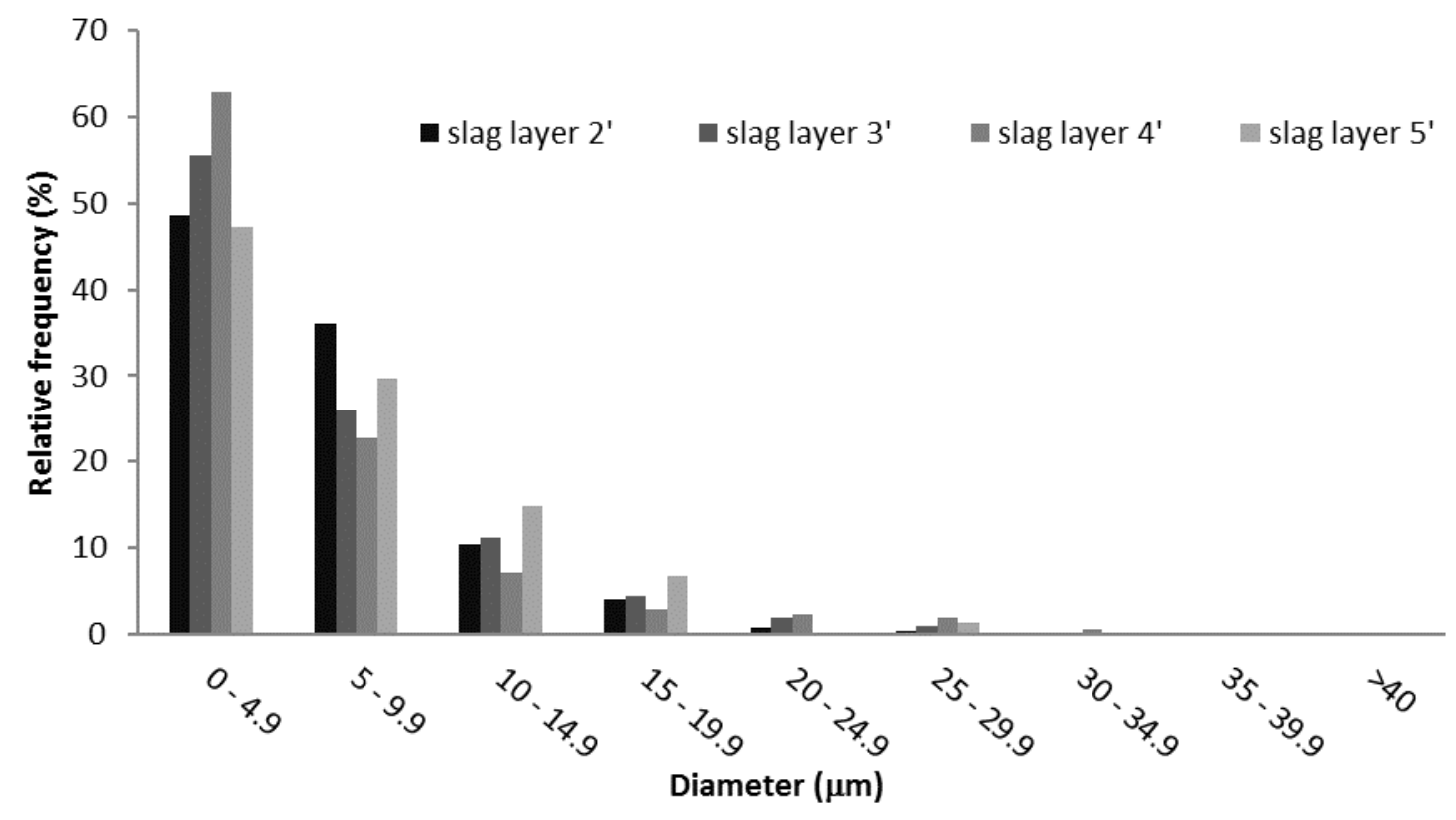

Figure 11 Size distribution of mechanically entrained droplets in crucible B, quenched after 20 min sedimentation 


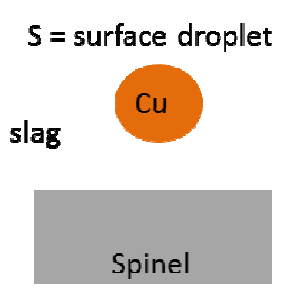

Before attachment
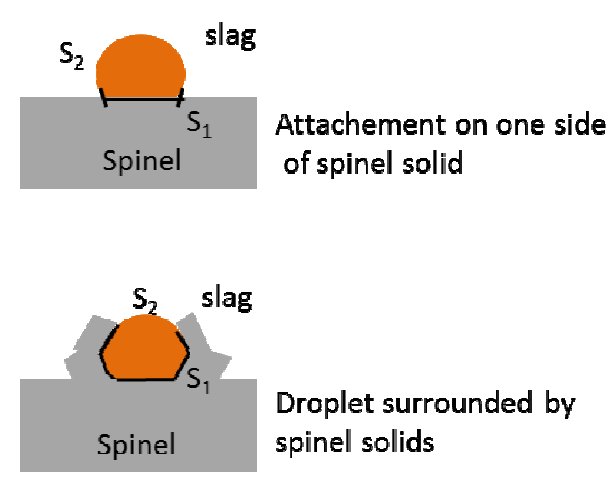

Figure 12 Schematic representation of a copper droplet before and after attachment to a spinel solid in the slag phase. Two types of attachment are considered: the attachment one side of spinel solid, and droplets which are surrounded by spinel solids $(S=$ surface area copper droplet before attachment, $S_{1}=$ contact area spinel and copper after attachment, $S_{2}=$ contact area slag and copper after attachment)

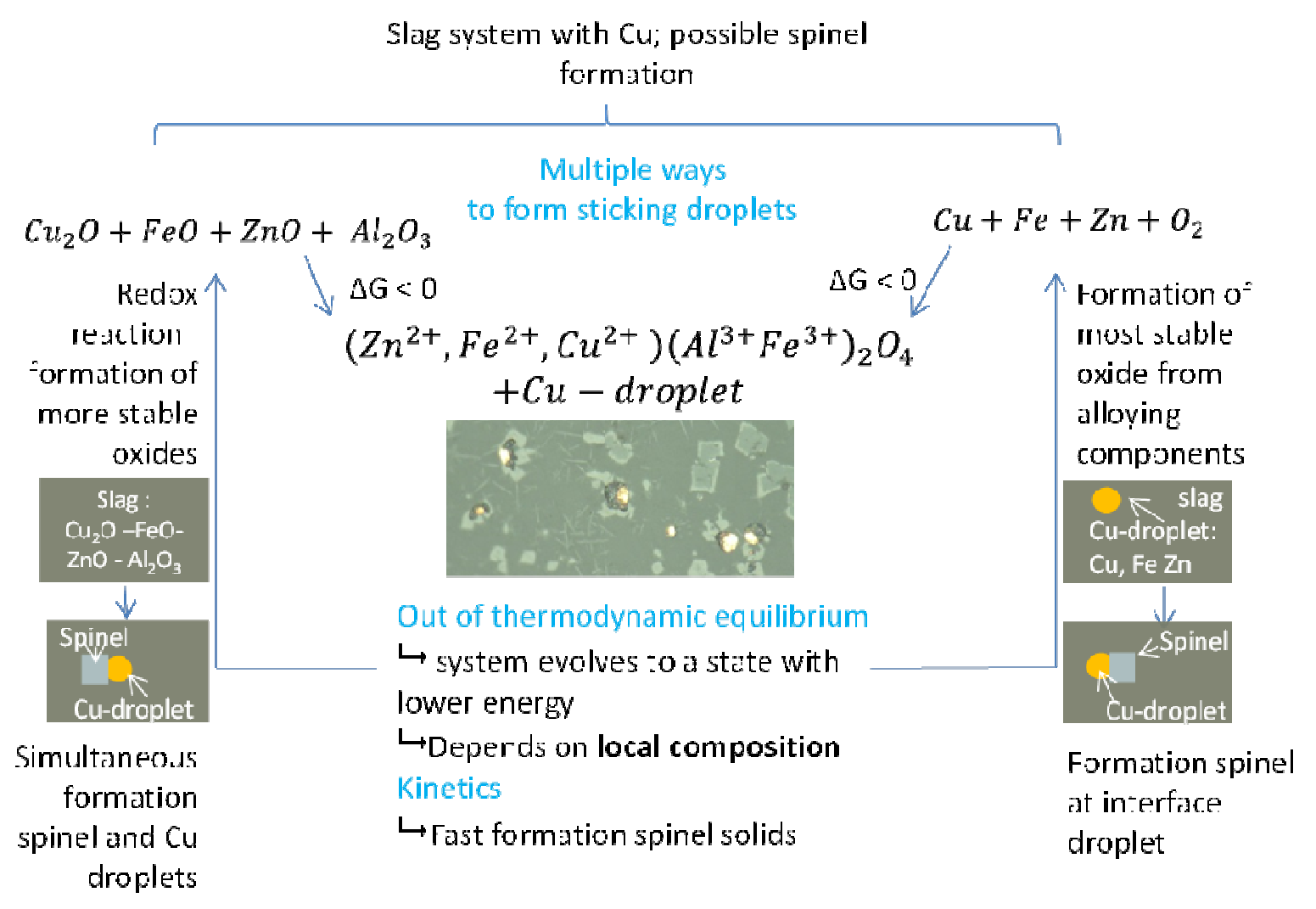

Figure 13 Possible reaction scheme to explain the origin of copper droplets sticking to spinel particles, including two possible pathways are suggested 


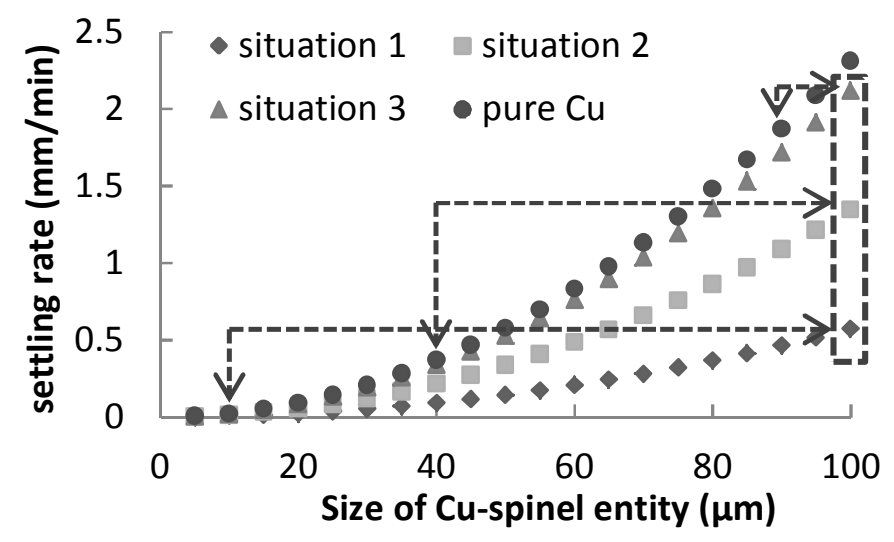

Figure 14 Calculated settling rate as a function of the size of the 'Cu-droplet - spinel' entity for each situation and pure copper. Additionally, the settling rate of a 'Cu-droplet-spinel' entity of $100 \mu \mathrm{m}$ is compared with the settling rate of an 'isolated' copper droplet, having a similar diameter as the copper droplet in the spinel entity, which is indicated by the arrows.

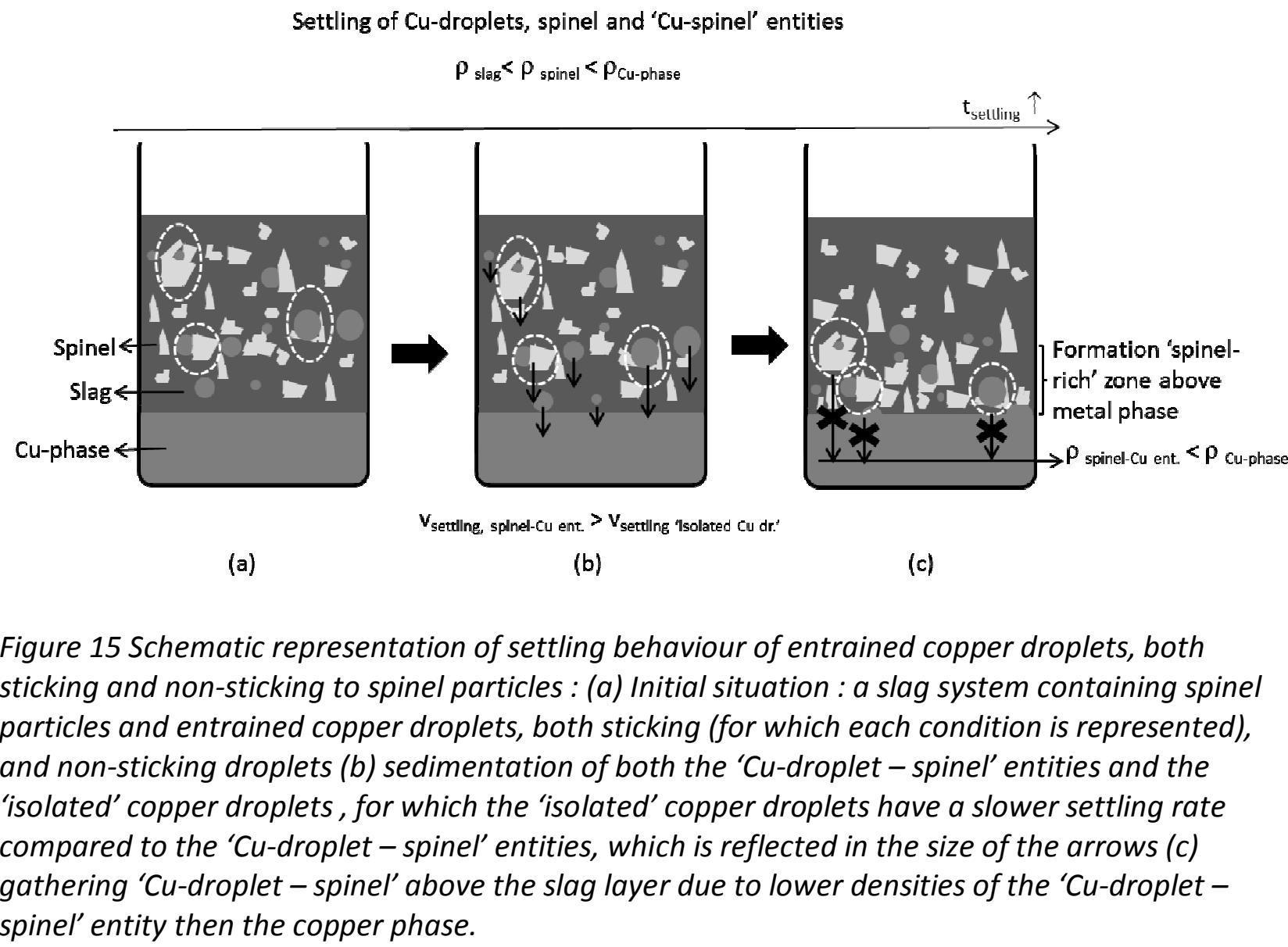

